Geosci. Model Dev. Discuss., 4, 385-417, 2011

www.geosci-model-dev-discuss.net/4/385/2011/

doi:10.5194/gmdd-4-385-2011

(c) Author(s) 2011. CC Attribution 3.0 License.

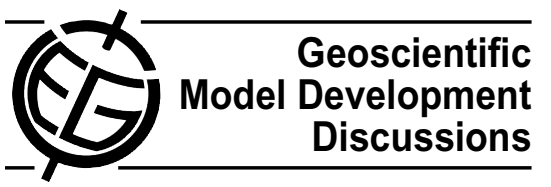

GMDD

$4,385-417,2011$

This discussion paper is/has been under review for the journal Geoscientific Model

Development (GMD). Please refer to the corresponding final paper in GMD if available.

\title{
An aerosol dynamics model for simulating particle formation and growth in a mixed flow chamber
}

M. Vesterinen ${ }^{1}$, H. Korhonen ${ }^{2}$, J. Joutsensaari ${ }^{1}$, P. Yli-Pirilä ${ }^{3}$, A. Laaksonen ${ }^{1,4}$, and K. E. J. Lehtinen ${ }^{1,2}$

${ }^{1}$ Department of Applied Physics, University of Eastern Finland, Kuopio, Finland

${ }^{2}$ The Finnish Meteorological Institute, Kuopio Unit, University of Eastern Finland, Kuopio, Finland

${ }^{3}$ Department of Environmental Science, University of Eastern Finland, Kuopio, Finland

${ }^{4}$ The Finnish Meteorological Institute, Helsinki, Finland

Received: 21 December 2010 - Accepted: 24 January 2011 - Published: 15 February 2011

Correspondence to: M. Vesterinen (milko.vesterinen @uef.fi)

Published by Copernicus Publications on behalf of the European Geosciences Union.

Modeling of aerosol dynamics in a mixed

flow chamber

M. Vesterinen et al.

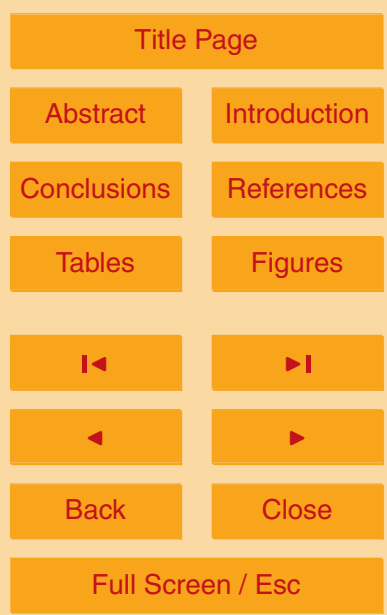

Printer-friendly Version

Interactive Discussion

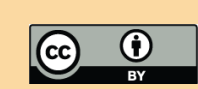




\section{Abstract}

In this work we model the aerosol size distribution dynamics in a mixed flow chamber in which new particles are formed via nucleation and subsequent condensation of oxidation products of VOCs emitted from Norway spruce seedlings. The micro5 physical processes included in the model are nucleation, condensation, deposition and coagulation. The aerosol dynamics in the chamber is a competition between aerosol growth and scavenging/deposition which results in a cyclic particle formation process. With a simple 1-product model, in which the formed gas is able to both condense to the particles and nucleate, we are able to catch both the oscillatory features of the particle formation process and the evolution of the number concentration in a reasonable way. The gas-phase chemistry was adjusted using pre-estimated reaction rate constant in the simulations and the particle deposition rate as a function of size was determined experimentally. Despite this, some of the essential features of the physical properties of the aerosol population could still be captured and investigated without the detailed knowledge of the physical processes underlying the problem by using the constructed model. The size dependency of the wall loss coefficient was investigated using a slightly modified measurement set-up.

\section{Introduction}

\subsection{Background}

Organic matter dominates the composition of submicrometer aerosols (Yu et al., 1999; Kanakidou et al., 2005; Jimenez et al., 2009). In the atmosphere, the annual emissions of biogenic volatile organic compounds (neglecting methane) are approximated to vary from ca. 500 to $1150 \mathrm{Tg}$ carbon of which ca. $11 \%$ (one of a tenth) can be characterized as monoterpenes. Furthermore, it has been approximated that a quarter of that mass

GMDD

4, 385-417, 2011

\section{Modeling of aerosol dynamics in a mixed flow chamber}

M. Vesterinen et al.

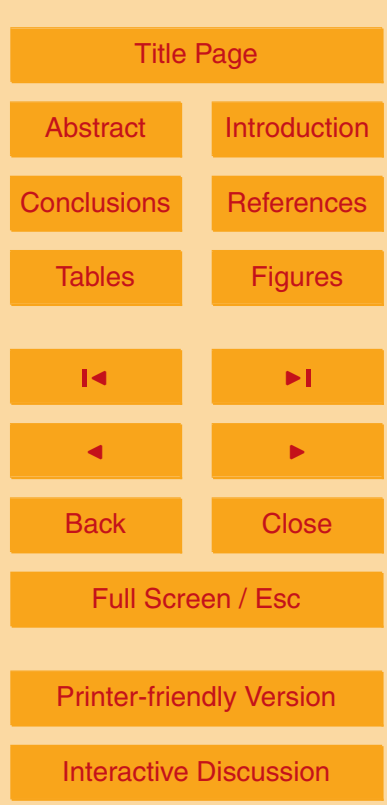


one of the most studied processes, atmospheric oxidation of monoterpenes that contributes to formation of secondary organic aerosol (SOA), is still not fully understood (Calogirou et al., 1999; Yu et al., 1999). However, a lot of effort has been put into it in modeling studies, the results being encouraging (e.g., Capouet et al., 2008). This 5 process is of a great importance, because typical reaction products of pinenes possess a sufficiently low vapor pressure to nucleate new particles even for very small amounts of reacted hydrocarbon (Hoppel et al., 2001). Volatile organic compounds (VOCs) are perhaps the most relevant species of atmospheric interest in this process, both anthropogenic (e.g. alkanes, alkenes, aromatics and carbonyls) and biogenic compounds 10 (terpenes and isoprenes). Organic compounds contribute therefore significantly to the total aerosol mass through the mass transfer (Svendby et al., 2008).

Consequently, the particulate phase total organic mass concentration is increased due to low vapor pressure organic compounds that are formed in oxidation processes of different hydrocarbons. Detailed understanding of the partitioning of biogenic hy15 drocarbons to the aerosol phase is important when trying to quantify their aerosol forming potential. There are, however, several different processes that can be associated with SOA. The understanding of the most important SOA processes require information about the forming mechanisms of low- and semi-volatility organics and e.g. semi-volatile compounds can either be locked in the condensed phase or be present in both the gas and particle phase. Modeling-based studies, therefore, suffer from the lack of quantitative information of the phenomena occurring in different phases, not to mention the nucleation of new particles and different partitioning processes (Pratsinis et al., 1986). Therefore, it is consistent that more and more scientific interest has been pointed to the SOA formation process occurring in the precisely controlled laboratory experiments. These experiments work as a complementary to field measurements.

The basic properties of the experimental laboratory smog chamber systems have been described in literature (Kleindienst et al., 1999). A typical chamber has a rectangular shape with a volume of $2-60 \mathrm{~m}^{3}$ and for practical reasons it is usually coated using Teflon (Odum et al., 1996; Bowman et al., 1997; Cocker et al., 2001). The
GMDD

4, 385-417, 2011

\section{Modeling of aerosol dynamics in a mixed flow chamber}

M. Vesterinen et al.

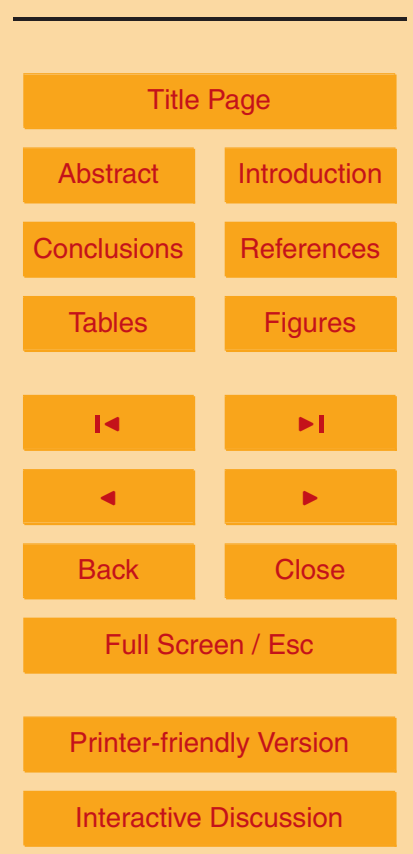


importance of the chamber studies was clarified by VanReken et al. (2006): chamber studies offer a very simplified, but effective method, for obtaining information about the known and unknown species in VOC related SOA formation. From the modeling point of view, they offer an optimal research environment for both partitioning (Pankow, 5 1994a,b; Odum, 1996) and dynamical models (e.g., Bowman et al., 1997).

A special case of chambers called "continuous flow chambers" (a.k.a. reactors) have been used to study the aerosol dynamics both in laboratory experiments and in studies induced by industry needs. Flow reactors differ from standard smog chambers crucially, because now the carrier gas is in movement through the volume. This has an important 10 effect on the aerosol dynamics inside the chamber. Other special characteristics of the flow reactors have been described in the literature (Crump and Seinfeld, 1980; Friedlander, 1983).

When performing flow chamber experiments, some special phenomena may occur that differ from the standard chamber studies: the movement of the carrier gas induces 15 an oscillatory behavior in the aerosol size distribution dynamics when suitable conditions are fulfilled. These oscillations were first noticed by Badger and Dryden back in the late 1930's, when they made a qualitative conclusion that the oscillation of the aerosol number concentration was a net result of nucleation and flow process in the volume (Badger and Dryden, 1939). Later, other scientists have reported similar results: Reiss et al. (1977) observed oscillatory behavior in the nucleation rate of new particles in a diffusion cloud chamber. Heist et al. (1980) ended up in similar results in their work.

Pratsinis et al. (1986) conducted a theoretical study to investigate the stability characteristics of an aerosol reactor, and in their model aerosol particles were formed by homogeneous nucleation from molecules via a chemical reaction of a zero-order. They investigated specially the effect of small perturbations to the steady state equilibrium but they neglected condensable gas monomer and particle wall losses, coagulation, subcritical cluster scavenging and Kelvin effect. Their work was based on the research performed by Friedlander (1983), who presented a theoretical framework that was used
GMDD

4, 385-417, 2011

\section{Modeling of aerosol dynamics in a mixed flow chamber}

M. Vesterinen et al.

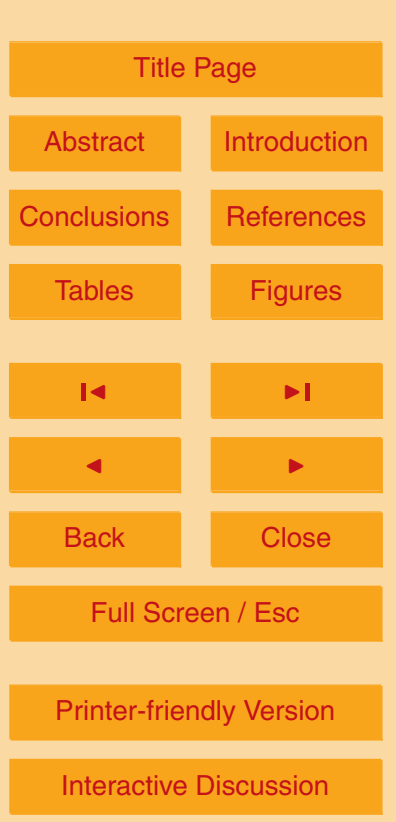


to describe the dynamic behavior of a set of four coupled differential equations describing the system. Furthermore, Crump and Seinfeld (1980) examined the basic features of aerosol behavior in the continuous stirred tank reactor. They presented an explicit aerosol size distribution in the case of a monodisperse feed aerosol during simulta5 neous coagulation, particle growth by vapor condensation and new particle formation. They investigated especially the qualitative features of aerosol formation and growth, and obtained exact analytical solutions to the aerosol balance equation in the case of constant kinetic coagulation coefficient and size-independent particle growth by vapor condensation. A perturbation solution was obtained for the case of linear volume de10 pendent particle growth and a monodisperse feed aerosol. Later, Seinfeld et al. (2003) continued this work by presenting an analytical solution for the steady-state aerosol size distribution achieved in a steady-state, continuous carrier gas flow. Their solution included gas-to-particle conversion in the case of two different gases and deposition to the wall, but effect of coagulation was neglected.

\subsection{Aims of this work}

In this work, we target at combining flow chamber measurement data to dynamical modeling, aiming for a computational tool suitable for investigating the coupled system formed by the different aerosol processes. The main goal of the paper is an attempt to construct a simple modeling tool that takes into account all basic aerosol processes relevant to model mixed flow chamber experiments. The investigation is focused on modeling the basic properties describing an aerosol population that include condensation sink, aerosol number concentration and their time-dependent (cyclic) behavior that was noticed in the measurements.

We use a simple aerosol model in which the nucleation of new particles is handled using a power-law relationship between nucleation rate and the gas-phase concentration of a single condensable gas. Besides nucleation, the numerical model takes into account both size-dependent coagulation and the condensational growth that shape the polydisperse particle distribution. In addition, the loss of the particles to the walls
GMDD

4, 385-417, 2011

\section{Modeling of aerosol dynamics in a mixed flow chamber}

M. Vesterinen et al.

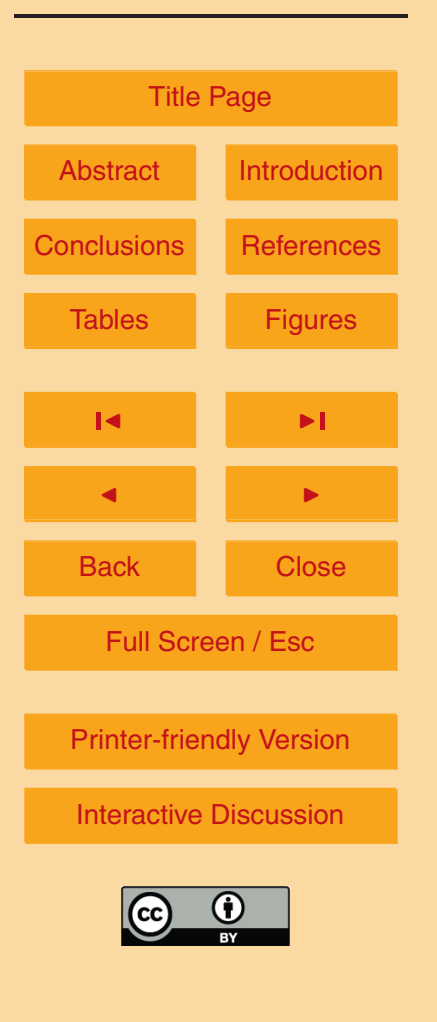


has been considered and the size dependency of the wall loss coefficient was investigated using a slightly modified measurement set-up. Our secondary effort is to present the essential properties of the aerosol population dynamics in a complex environment using as few model parameters as possible and try to offer a possible platform for future 5 studies in more demanding cases.

\section{Methods}

\subsection{Chamber experiment}

The SOA formation experiment analyzed in this study was carried out in a continuous flow reactor system, which consists of a plant enclosure and a reaction chamber (volume $2 \mathrm{~m}^{3}$, made of FEP film). Norway spruce (Picea abies) seedlings were used as VOC emitters. The bark of the seedlings was damaged by large pine weevils (Hylobius abietis) to induce the production of monoterpenes and other reactive compounds. Air flow from seedling headspace was mixed with an ozone-enriched air flow (ozone concentration $200 \pm 10 \mathrm{ppb}$ ) at the inlet of the reactor. The total air flow at the reac15 tion chamber was $36 \mathrm{l} / \mathrm{min}$ with average residence time of ca. $1 \mathrm{~h}$. At the beginning of the trials, VOCs from seedlings were introduced to the chamber for about one hour before starting the ozone addition. The duration of the chamber experiment was ca. $24 \mathrm{~h}$. The diurnal cycle was mimicked by turning off the lights over plant chamber from $22: 00$ to $06: 00$. The reaction chamber relative humidity $(\mathrm{RH})$ varied between $6-8 \%$ and temperature maintained between $295-297 \mathrm{~K}$. The measurement set-up is presented in Fig. 1.

During the experiment VOC samples were collected on Tenax-TA adsorbent and the samples were analyzed by a gas chromatograph-mass spectrometer. Also ozone (DASIBI 1008-RS O $\mathrm{O}_{3}$ analyzer), $\mathrm{NO}_{\mathrm{x}}\left(\mathrm{AC} 30 \mathrm{M} \mathrm{NO}\right.$ analyzer) and $\mathrm{SO}_{2}\left(\mathrm{AF} 21 \mathrm{M} \mathrm{SO}_{2}\right.$ 25 analyzer) concentrations were monitored. Particle size distributions between 16$723 \mathrm{~nm}$ were measured every three minutes using a scanning mobility particle sizer

\section{GMDD}

4, 385-417, 2011

\section{Modeling of aerosol dynamics in a mixed flow chamber}

M. Vesterinen et al.

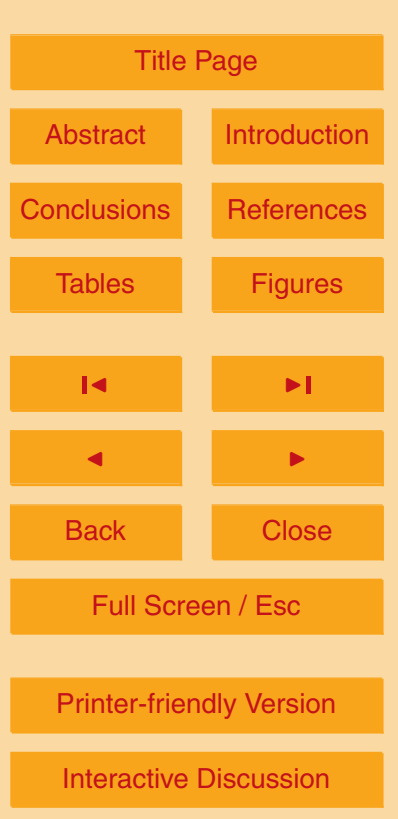

Interactive Discussion 
(SMPS), consisting of a TSI Model 3071A electrostatic classifier and a TSI Model 3022A CPC. VOC emission from seedlings consisted mainly of $\beta$-pinene, $\alpha$-pinene, $3-$ carene, limonene, $\beta$-phellandrene and myrcene (representing $85 \%$ of total VOC emission).

5 In addition to the SOA experiment, another set of measurements was made to determine the size-dependent wall loss coefficients of the aerosol particles inside the chamber. In these measurements, a continuous particle flux was conducted to the chamber using a constant air flow through the volume. The aerosol number size distribution between $16-736 \mathrm{~nm}$ was fixed at the inlet, and the number size distribution was 10 monitored inside the chamber as a function of time. The measurement period lasted $3 \mathrm{~h}$ during which the number size distribution settled to steady-state. There were no other processes producing aerosols and no organic vapors present in the gas-phase and therefore the only two processes shaping the final aerosol number distribution were coagulation and the wall loss/air exchange processes. The wall loss coefficients were determined using an optimization algorithm described in detail in Sect. 2.2.1.

\subsection{Aerosol model}

\subsubsection{Particle microphysics}

The time evolution of the aerosol population inside the flow reactor was studied with a new aerosol dynamics code developed for this study based on the UHMA model 20 (Korhonen et al., 2004). The basic aerosol processes included in the model are coagulation, deposition to the chamber walls, the condensational growth and nucleation. The particle concentration can also change due to the continuous flow of the carrier gas (air) through the chamber volume. Aerosol size distribution and its time-dependent behavior are described using a fixed sectional method (Turco et al., 1979) with 130 size bins in the size range $1 \mathrm{~nm}-5 \mu \mathrm{m}$. The description of the aerosol dynamics includes ordinary differential equations of first degree that are solved using Euler forward method with a 0.5-s time step. At each time step, all physically relevant subroutines are executed
GMDD

4, 385-417, 2011

\section{Modeling of aerosol dynamics in a mixed flow chamber}

M. Vesterinen et al.

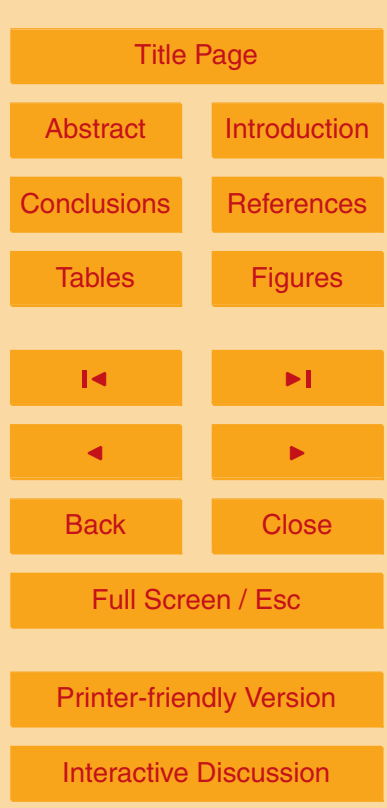


and all time-dependent variables updated.

The change in number concentration of the aerosol particles in each size section $j$ can be written as:

$$
\left(\frac{d N_{j}}{d t}\right)=\delta(j-1)\left(\frac{d N}{d t}\right)_{\text {nucl }}+\left(\frac{d N_{j}}{d t}\right)_{\text {cond }}+\left(\frac{d N_{j}}{d t}\right)_{\text {coag }}+\left(\frac{d N_{j}}{d t}\right)_{\frac{\text { wall }}{\text { flow }}}
$$

5 In our model, the coagulation and condensation processes are described based on the equations presented in Seinfeld and Pandis (1998). The coagulation kernel is based on the work of Fuchs and Sutugin (1971).

Since the exact nucleation mechanism inside the chamber is not known, we test several possible nucleation schemes. The nucleation rate is presented as

$$
\begin{array}{ll}
\left(\frac{d N}{d t}\right)_{\text {nucl }}=\frac{A}{\gamma}[\mathrm{CG}]^{\gamma}, & \gamma \neq 0 \\
\left(\frac{d N}{d t}\right)_{\text {nucl }}=A . & \gamma=0 .
\end{array}
$$

Here [CG] is the number concentration of the molecules of the nucleating gas. Different values for were tested (from 0 to 3 ) during the research and the units of the constant $A$ depend therefore on the factor $\gamma$. The coefficient $\frac{1}{\gamma}$ must be inserted on the right hand side of Eq. (2) (in case of $\gamma \neq 0$ ) because the particle formation rate is now comparable 15 to one of the $\gamma$ th part of the disappearance rate of the gas. Therefore, new particles are presumed to follow kinetics analogue to basic chemical processes of " $\gamma$ th" order occurring in gas-phase.

The effects of particle wall losses as well as of air exchange (air flow through the chamber) require additional considerations. Losses of aerosol in an enclosed vessel result from deposition due to Brownian diffusion and turbulent transport to the walls and especially for larger particles, from gravitational settling coefficient. Furthermore, the shape of the chamber has a great practical relevance (Crump and Seinfeld, 1981). In this work, particles' wall loss in size bin $j$ (with diameter of $D_{\mathrm{p}}$ ) was described as

GMDD

4, 385-417, 2011

\section{Modeling of aerosol dynamics in a mixed flow chamber}

M. Vesterinen et al.

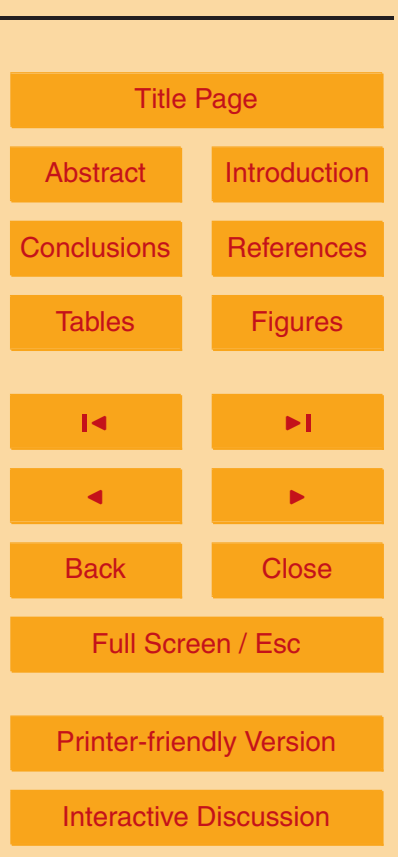

Interactive Discussion 
a first-order process respect to particle number concentration in each size class using a size-dependent loss coefficient

$$
\left(\frac{d N_{j}}{d t}\right)_{\text {wall }}=-\beta\left(D_{\mathrm{p}}\right) N_{j}
$$

On the other hand, the flow of the carrier gas has an effect both on the number concen5 tration of the aerosols and the concentration of the CG (and to that of hydrocarbon), thus changing the lifetime of the species in the gas-phase. By investigating the mass transport due to the air flow, we can write a differential equation for the "flow effect" that is mathematically similar to that of wall loss effect:

$$
\left(\frac{d N_{j}}{d t}\right)_{\text {flow }}=-\beta^{*} N_{j}=-\frac{\dot{q}}{V} N_{j}
$$

Here $\dot{q}$ is the air flow rate through the volume and $V$ is the total volume of the chamber. The $\beta^{*}$-factor for our set-up was ca. $3 \times 10^{-4} \mathrm{~s}^{-1}$. By noticing that Eqs. (3) and (4) are mathematically similar, we can integrate these two phenomena into one equation, thus making it possible to handle these processes as one from the modeling point of view.

Some analytical formulations for wall loss effect exist in literature, e.g., Crump and 15 Seinfeld (1981) who presented an analytical formulation for the aerosol size dependency of the $\beta$-coefficient. A literature search revealed that the approximated values of the coefficient varied between a couple of orders of magnitude $\left(10^{-6}-10^{-4} \mathrm{~s}^{-1}\right)$, depending on the size of the particles. On the other hand, several laboratory measurements suggest that $\beta$ has a time-dependency as well as a correlation with ambient conditions. As already mentioned by Park et al. (2001) the wall loss rate depends not only upon the size of the particles, but also upon polydispersity of the size distribution under consideration. For simplicity, we neglected additional theoretical considerations here and instead, we decided to search for an optimal function for the wall loss size dependence to match to our experimental wall loss data. We used the following

GMDD

4, 385-417, 2011

\section{Modeling of aerosol dynamics in a mixed flow chamber}

M. Vesterinen et al.

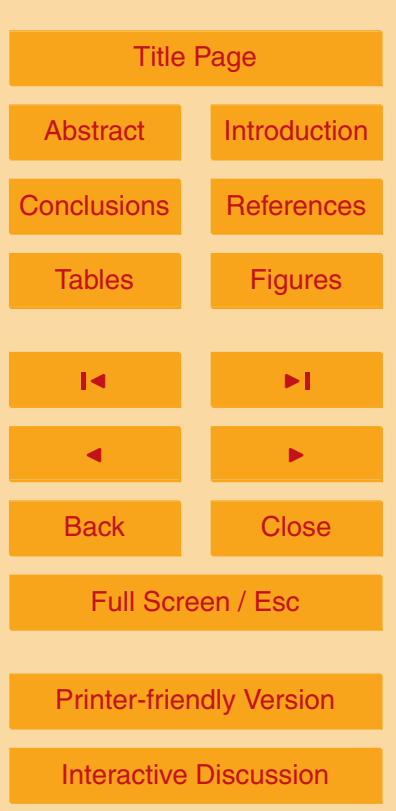

Interactive Discussion 
equation for which the numerical values of $A, B, C$ and $D$ were searched using a fit procedure:

$\beta\left(D_{\mathrm{p}}\right)=10^{y}, \quad$ where $y=A *\left(\log \left[D_{\mathrm{p}}\right]\right)^{2}+B *\left(\log \left[D_{\mathrm{p}}\right]\right)+C *\left(\log \left[D_{\mathrm{p}}\right]\right)^{D}$

Equation (5) can be justified heuristically when investigating the shapes of previously 5 obtained fitted or theoretical curves for wall loss coefficients: in log-log scale, the curves follow somewhat the shapes of a parabola (Crump and Seinfeld, 1981; Crump et al., 1983; McMurry and Grosjean, 1985; McMurry and Rader, 1985; Park et al., 2001; Hussein et al., 2009). Therefore, when the actual fit procedure is performed in linear scale as it was the case in this study, a form of Eq. (5) must be used.

To find the optimal values of $A, B, C$ and $D$, we initialized the aerosol model with the measured initial size distribution from the wall loss experiment and ran the model using only coagulation and wall loss/air exchange code blocks. The results of the model were used as an object function output for Nelder-Mead algorithm that is one of the best known algorithms for multidimensional unconstrained optimization without the Jacobian matrix (Nelder and Mead, 1965). The variable to be minimized was determined to be the relative error between measured and modeled size distributions.

The measured size distribution as well as the calculated size distribution at the end of the 3-h simulation is presented in Fig. $2 \mathrm{a}$ and the optimized wall loss coefficient in Fig. $2 \mathrm{~b}$. The obtained best fit values for parameters $A, B, C$ and $D$ are listed in the figure caption. Figure 2 shows that the obtained steady-state distribution is in a very good agreement with measurements. To ensure that the simulated system is in a steadystate, we continued to simulate the aerosol size distribution for 7 more hours. After $10 \mathrm{~h}$ simulation, there were no changes in size distribution compared to that after $3 \mathrm{~h}$ and steady-state conditions were concluded to occur already after $3 \mathrm{~h}$ simulation.

25 However, two important points must be stressed here: first, there is now a reason to believe that the air exchange effect, as a whole, has a larger impact here to the particle concentration over the whole size range compared to effect of the wall loss term only. The wall loss term has a larger effect only when diameter of the particles is $\approx 65 \mathrm{~nm}$

GMDD

$4,385-417,2011$

\section{Modeling of aerosol dynamics in a mixed flow chamber}

M. Vesterinen et al.

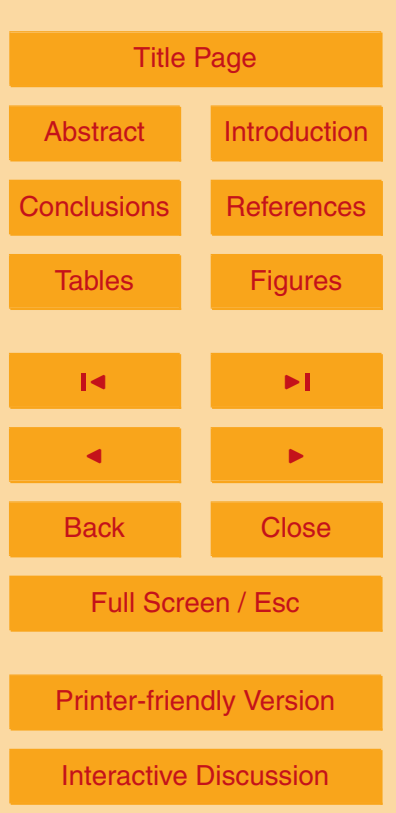

Interactive Discussion 
and below. Second, the fit was performed for particles whose diameter varied between 15 and $736.5 \mathrm{~nm}$, while the model simulates particles in the size range of $1 \mathrm{~nm}$ to $5 \mu \mathrm{m}$. If the obtained wall loss function is extrapolated to the very smallest particles classes $(1 \mathrm{~nm}-1.5 \mathrm{~nm})$, we observe that the values of the loss coefficients increase rapidly 5 approaching the value $1 \mathrm{~s}^{-1}$, producing several order of magnitude larger values for loss coefficients than in the case of $15 \mathrm{~nm}$ particles. Therefore, we decided to keep the wall loss coefficient constant using value $0.0016 \mathrm{~s}^{-1}\left(5.76 \mathrm{~h}^{-1}\right)$ for particles with diameter $<15 \mathrm{~nm}$. This is close to the values found by Hussein et al. (2009) and, in fact, Verheggen et al. (2007) found similar values for the gaseous compounds with 0 a diffusion coefficient of $0.1 \mathrm{~cm}^{2} \mathrm{~s}^{-1}$ in their model.

The air flow rate through the chamber is higher than used in other reactor studies. In fact, the shape of the wall loss curve indicates that the presence of turbulence cannot be excluded (see Hussein et al., 2009 and reference sources therein). However, the shape of Eq. (5) guarantees that non-physical results cannot occur in the fit, that is, 15 negative wall loss coefficients in any particle size class. In addition to this, obtained steady-state distribution is in a very good agreement with measurements as can be seen in Fig. $2 a$.

\subsubsection{Simplified gas-phase chemistry}

In order to test our model, we represent the gas-phase chemistry with a highly simplified scheme: the VOCs released from the plants are simulated with one lumped compound ( $\mathrm{HC}$, hydrocarbons), as are their condensable ozonolysis products (CG, condensable gases). The HC compound is assumed to have a very high volatility, a realistic but an adjustable oxidation rate with a molar mass of $180 \mathrm{~g} \mathrm{~mol}^{-1}$.

The simulation of $\mathrm{HC}$ and ozone are based on the chamber measurements: the 25 concentration of $\mathrm{HC}$ was measured both at the inlet and the outlet of the chamber, whereas for ozone, only the inlet concentration was measured. Therefore, the absolute concentration of each gas component inside the chamber is only approximately known. However, if one knows the constraints of the system (carrier gas exchange rate, the

GMDD

4, 385-417, 2011

\section{Modeling of aerosol dynamics in a mixed flow chamber}

M. Vesterinen et al.

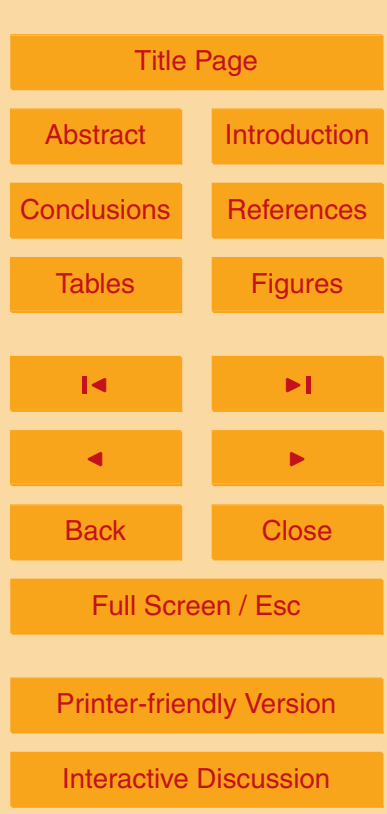

Interactive Discussion 
physical dimensions of the chamber and simple gas-phase chemistry) and the growth rates of the particles inside the chamber via measurements, then we can adjust the unknown parameters so that modeling results correspond to the data. The ozone concentration at the inlet was kept steady and continuously monitored (ca. $200 \mathrm{ppb}$ ), 5 so if the air exchange rate through the chamber is known, the concentration profile can be simulated. In case of $\mathrm{HC}$, it was approximated that the total concentration inside the chamber changed from ca. $45-50 \mathrm{ppb}$ to ca. 15-17 ppb (ozone feed was initialized after $2.2 \mathrm{~h}$ ) during the experiment and the change was not purely linear, but rather an decreasing exponential curve.

The time evolution of $\mathrm{HC}$ and ozone concentrations can therefore be written as

$\frac{d([\mathrm{HC}])_{\text {in }}}{d t}=\beta^{*}\left([\mathrm{HC}]_{\text {inlet }}-[\mathrm{HC}]_{\text {outlet }}\right)-k_{\text {ox }}[\mathrm{HC}]_{\text {in }}\left[\mathrm{O}_{3}\right]_{\text {in }}$

$\frac{d\left(\left[\mathrm{O}_{3}\right]\right)_{\text {in }}}{d t}=\beta^{*}\left[\mathrm{O}_{3}\right]_{\text {inlet }}-\beta^{*}\left[\mathrm{O}_{3}\right]_{\text {in }}-k_{\text {ox }}[\mathrm{HC}]_{\text {in }}\left[\mathrm{O}_{3}\right]_{\text {in }}$

The factor describes the carrier gas flow and was in our set-up $3 \times 10^{-4} \mathrm{~s}^{-1}$. Variables inside square brackets are number concentrations of corresponding gases at different

points of the measurement chamber (inside the chamber is marked "in", etc.).

The time-dependence of the nucleating and condensing organic oxidation product $\left[\mathrm{CG}_{1}\right]$ in the gas-phase can be written using mass balance as

$$
\begin{aligned}
\frac{d\left(\left[\mathrm{CG}_{1}\right]\right)}{d t}= & \alpha k_{\mathrm{ox}}[\mathrm{HC}]_{\mathrm{in}}\left[\mathrm{O}_{3}\right]_{\mathrm{in}}-\sum_{j=1}^{130} N_{j} 2 \pi\left(\frac{6}{\pi} V_{j}\right)^{1 / 3} \beta_{\mathrm{m}} D\left(\left[\mathrm{CG}_{1}\right]-\left[\mathrm{CG}_{1}\right]_{\text {equil }, j}\right) \\
& -\beta^{*}\left[\mathrm{CG}_{1}\right]-A\left[\mathrm{CG}_{1}\right]^{\gamma}
\end{aligned}
$$

20 where $N_{j}$ is the aerosol particle concentration in the size bin $j$, is volume of the particle in size bin $j, D$ is the diffusion coefficient and $\beta_{\mathrm{m}}$ is the transition regime coefficient (Fuchs and Sutugin, 1971; Reid et al., 1987). The term $\alpha$ is so called molar yield (no units), i.e. when $\alpha=0.5,1 \mathrm{~mol}$ of $\mathrm{HC}$ produces $0.5 \mathrm{~mol}$ of $\mathrm{CG}$ in the oxidation process. The number concentration of gas is marked, as in Eqs. (6) and (7), using 396
GMDD

$4,385-417,2011$

\section{Modeling of aerosol dynamics in a mixed flow chamber}

M. Vesterinen et al.

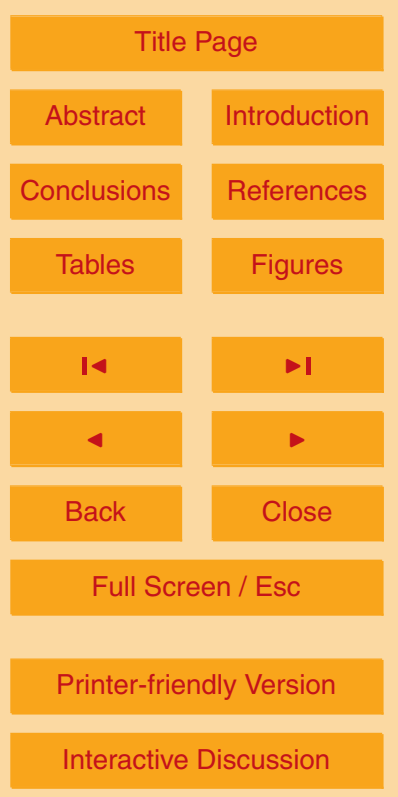

Interactive Discussion 
square brackets. The gas phase concentration of $C G$ is therefore the same for each size class at each time step and it is not updated until the next time step. In this work, we use so called 1-product model where gas-phase chemistry produces only one condensing species with low volatility. This compound participates both in nucleation 5 and condensational growth, whereas in the case of 2-product model we could have another compound formed in the gas phase with different volatility and molar yield. 2-product model offers more flexibility to control the modeled condensational growth (and/or other processes), but it requires at least two additional parameters to the model.

The first term on the right side of Eq. (8) describes the formation rate of CG 10 molecules (in units $\mathrm{m}_{\text {air }}^{-3} \mathrm{~s}^{-1}$ ) from the ozonolysis of parent hydrocarbons. The second term describes the molecular flux of the CG molecules to the surface of the particles summed over every size section, where $[C G]_{\text {equil }}$ has a size dependence due to the Kelvin effect. If the terms inside the parentheses are dropped out, the second term is also known as inverse lifetime or condensational sink (Kulmala, 2001) and it can be used effectively to describe some of the essential features of the aerosol populations. The third and fourth terms describe the loss of the CG molecules due to air exchange and nucleation, respectively. Here we have neglected here the loss of the gas to the chamber's walls based on the considerations in Sect. 4.

Using the equations above, the growth/shrinkage of particles at each time step in each size bin can be easily calculated by using the estimated molecular volume of CG and the information of the particle size at the previous time step. The effect of particle surface curvature on aerosol evaporation (the Kelvin effect) can be excluded if and only if we presume that the equilibrium vapor pressure on the particles in each size section is negligible. In that case the concentration of CG in particle phase would increase at

\section{GMDD}

4, 385-417, 2011

\section{Modeling of aerosol dynamics in a mixed flow chamber}

M. Vesterinen et al.

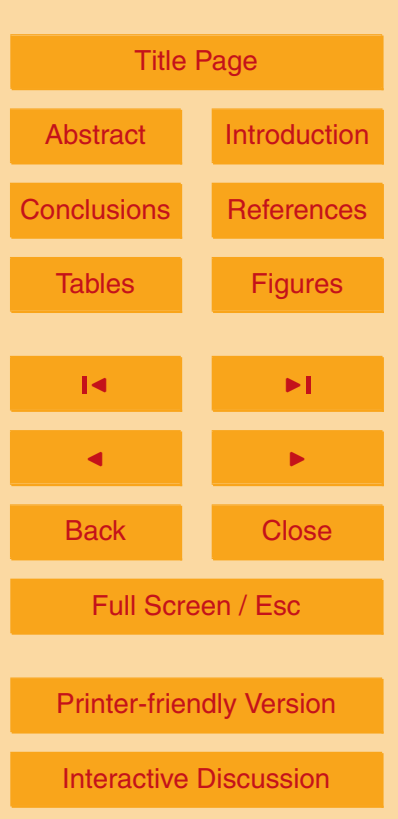




\section{Results}

\subsection{Gas concentrations deducted from the chamber experiments}

During the SOA chamber experiment, the total concentration of $\mathrm{HC}$ at carrier gas inlet and outlet were measured at certain intervals indicated in Fig. 3a. By investigating the 5 concentration changes with time, we can approximate the effective $\mathrm{HC}$ consumption in the oxidation reaction (or more specifically, estimate the effective oxidation reaction rate in the model). It was estimated that the $\mathrm{HC}$ concentration inside the chamber was close to that measured at the outlet, so by forcing the modeled results near to those values, we obtain an effective reaction rate coefficient $\left(k_{\mathrm{ox}}\right)$. It is worth noting that even relatively small modifications (ca. $30 \%$ ) to the obtained $k_{\text {ox }}$ will change the modeled gas-phase results considerably, which gives a reason to believe that the calculated effective reaction rate constant is approximately correct under the made assumptions.

The obtained profiles for $\mathrm{HC}$ and ozone are plotted in Fig. 3. It can be observed that the measured $\mathrm{HC}$ inlet concentration is $40 \mathrm{ppb}$ at the beginning and the profile remains somewhat linear after $4.5 \mathrm{~h}$, but there are minor changes during the first couple of hours (Fig. 3a). On the other hand, the measured outlet concentration exceeds the value of inlet concentration during the first four hours. This means that the $\mathrm{HC}$ concentration inside the chamber is not negligible during first hours and therefore it is difficult to estimate the amount of hydrocarbon compounds at the outset. The modeled profile that has a shape of an exponential curve is due to solution of Eqs. (6) and (7) and it was forced to obtain values near the outlet concentration. In Fig. 3b the initial ozone concentration is zero but it approaches the value measured at the inlet (ca. $200 \mathrm{ppb}$ ), which is consistent to the measurement. However, the excess ozone concentration is large compared to that consumed in chemical reaction, so the changes

The molar yield $\alpha$ of the condensable organic compound CG was estimated from the growth rate of the particles during the nucleation bursts. The growth rate was obtained applying a linear fit to the size distribution data and varied between 70 and $110 \mathrm{~nm} \mathrm{~h}^{-1}$.

\section{Modeling of aerosol dynamics in a mixed flow chamber}

M. Vesterinen et al.

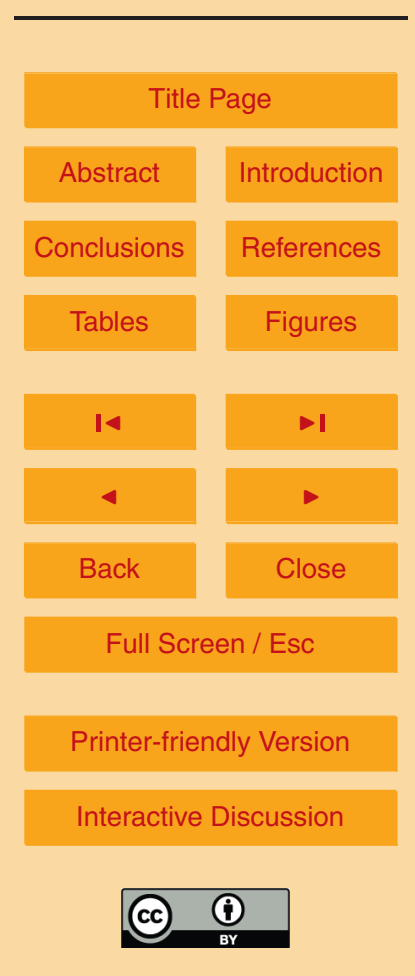


The obtained rates are very high compared to those of measured in the nature during regional nucleation events (Kulmala et al., 1998; Dal Maso et al., 2002; Hamed et al., 2007; Jaatinen, 2008). The high growth rates can be explained by the chamber conditions: while the hydrocarbon sources were natural (spruce seedlings), the 5 emitted VOCs were not allowed to dilute to atmospheric concentrations. Furthermore, the ozone concentration was kept high (ca. $200 \mathrm{ppb}$ ) during the measurement. Since the growth rate can be assumed to be proportional to the gas phase concentration of CG (presuming that the growth by coagulation is negligible), we were able to give estimates for the CG concentration during the growth periods. Using these presumptions, 10 the condensable gas should have a concentration of magnitude $7-12 \times 10^{14} \mathrm{~m}_{\text {air }}^{-3}$. Furthermore, as the modeled $\mathrm{HC}$ concentration was found to be comparable to the value that it was estimated to be inside the chamber, we can obtain a rough estimate of the lower limit for the condensable gas' molar yield (ca. 0.17).

\subsection{Aerosol model results}

15 The aim of the aerosol model runs was to (1) investigate whether the nucleating organic vapor can be responsible also for the particle growth in the chamber and (2) constrain the unknown variables of the system (i.e. molar yield $\alpha$, nucleation exponent $\gamma$ and nucleation prefactor $A$ ). For this purpose, we conducted a larger set of simulations varying these variables and comparing the obtained results to the observed behavior of 20 the aerosol population in the chamber. Overall, the best "fits" were chosen to be those model runs that produced satisfactory visual correspondence simultaneously for both sink and number concentration. The simulation and measurement data between $0-5 \mathrm{~h}$ was neglected (the first nucleation peak), because the $\mathrm{HC}$ concentration inside the chamber differed, most probably exceeded, the value that we were able to extrapolate 25 from the HC measurement data. Since preliminary testing indicated that the smallest values for the $\gamma$ succeeded to produce satisfactory results for the sink and for the number concentration simultaneously, we left out nucleation exponents higher than 3 .
GMDD

$4,385-417,2011$

\section{Modeling of aerosol dynamics in a mixed flow chamber}

M. Vesterinen et al.

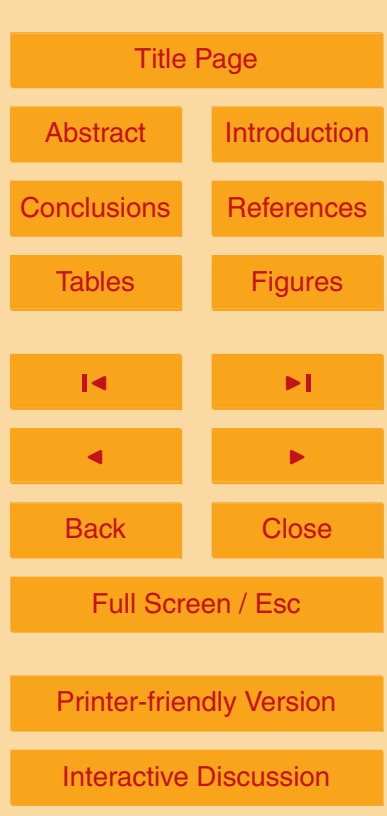


All the model runs were initialized with a background aerosol consisting of one lognormal mode $\left(d_{\mathrm{g}}=7.5 \mathrm{~nm}, \sigma=1.01\right.$ and $\left.N=100 \mathrm{~cm}^{-3}\right)$. The simulation was forced with the $\mathrm{HC}$ and ozone profiles calculated in Sect. 3.1, and thus nucleation initiated after ca. $2.2 \mathrm{~h}$ when the inlet feed of ozone started. The chamber temperature was set 5 to $296.0 \mathrm{~K}$ and the pressure to $1 \mathrm{~atm}$.

Figures 4 and 5 show the dependence of the modeled condensation sink (CS) and the particle number concentration (NC) on the simulated nucleation exponent $\gamma$. The investigation of the model runs reveals that as factor $\gamma$ increases, the growth behavior of aerosol population gets more detailed and separate nucleation bursts appear more 10 clearly. This can be seen clearly in case of number concentration in Fig. 5. This indicates that the model is more sensitive to cyclic behavior (more nonlinear) in case of a larger exponent. The sensitivity is not as clearly seen in the cases of modeled results of CS.

As can be expected, the trends of measured and modeled sinks follow the trend 15 of the total hydrocarbon concentration inside the chamber. The best match in our model runs is obtained by setting $\gamma=1$. In other cases, the second peak after first $6 \mathrm{~h}$ occurs prematurely $(\gamma=0)$ or there is a time lag (cases $\gamma=2$ and 3$)$. The decreasing trends in modeled results are observable and relative close to measured values in all cases. As mentioned before, the first nucleation peak was not investigated in detail due to unknown $\mathrm{HC}$ concentration inside the chamber at the beginning. However, all the model runs clearly underestimate the CS during this peak indicating that the modeled concentration of the condensable compound is too low in the beginning of the simulation.

The measured nucleation peaks are more clearly present in the simulated NC (Fig. 5) 25 and the simulations indicate four clear nucleation events during first $12 \mathrm{~h}$, out of which the first nucleation event is several times stronger than the last events due the excess hydrocarbon present in the chamber. Modeled NC has the best correspondence with the measurements if $\gamma$ has a value of 0 or 1 . As $\gamma$ increases, the cyclic behavior (damped oscillations) increases during the first $8 \mathrm{~h}$. In fact, the modeled profiles in
GMDD

4, 385-417, 2011

\section{Modeling of aerosol dynamics in a mixed flow chamber}

M. Vesterinen et al.

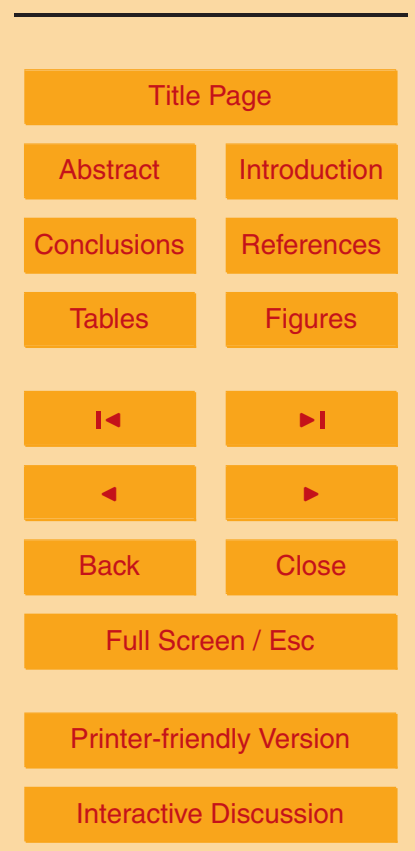


the case of the two largest values of $\gamma$ are very similar. In all modeled cases NC approaches asymptotically a constant value as simulation time increases although there is a decreasing trend in all model cases (as it is with the case of modeled CS). Contrary to the sink data in Fig. 4, the measured NC does not show a clear decreasing trend 5 after $15 \mathrm{~h}$. This indicates that either the particle removal processes are overestimated or the nucleation and growth are underestimated in the model towards the end of the simulation.

The measurement data (CS or NC) shows no large nucleation bursts after $15 \mathrm{~h}$ of measurements. Both sink and number concentration remains relatively constant - in 10 fact, the sink data has a slightly growing trend, whereas the number concentration of the particles remains nearly constant. Therefore, it can be deduced that the system is in a steady-state. It can also be seen that there is a time lag between measured NC and CS peaks: the sink peaks ca. $1 \mathrm{~h}$ later compared to number concentration. This is a consequence of the fact that sink is a product of both NC and the effective surface 15 area of the particle, the latter of which keeps growing due to condensation even after $\mathrm{NC}$ has reached its maximum and starts to decrease due removal processes.

The nucleation rate of the particles as a function of time for different $\gamma$ values is plotted in Fig. 6. Interestingly, the nucleation rates in the case of $\gamma=1$ are ca. two times higher than in the case of $\gamma=0$, even if the modeled condensational sink and aerosol number concentration do not differ significantly between these cases and give the best match with the measurements. Furthermore, the modeled nucleation rate profiles have similar curves in the cases of $\gamma=2$ and $\gamma=3$. These curves are located between the curves obtained for $\gamma=0$ and $\gamma=1$.

The gas-phase concentrations in the case of different $\gamma$ are plotted in Fig. 7. At the 25 end of the simulation, all curves settle to approximately same value (ca. $8 \times 10^{14} \mathrm{~m}_{\text {air }}^{-3}$ ). An additional observation is that if saturation concentration exceeds the value of $1 \times 10^{12} \mathrm{~m}_{\text {air }}^{-3}$, the behavior of the system changes radically (not presented here). This indicates that Kelvin effect (which can increase the equilibrium vapor pressure by several orders of magnitudes in the cases of the smallest particle sizes) has a large effect
GMDD

$4,385-417,2011$

\section{Modeling of aerosol dynamics in a mixed flow chamber}

M. Vesterinen et al.

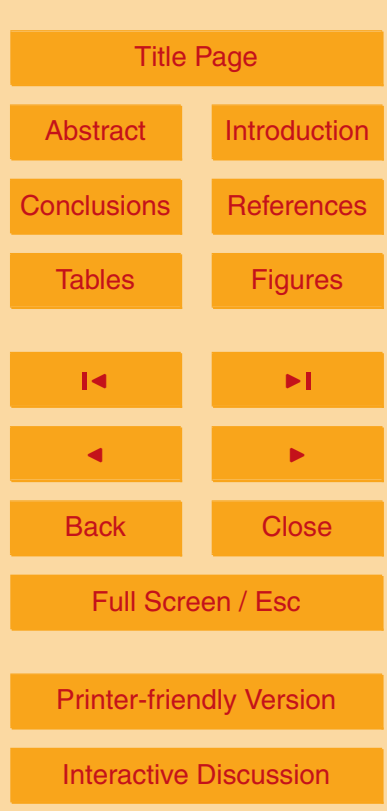


to the cyclic behavior especially in the case of 1-product model and when saturation concentration is above this threshold value.

The time evolution of the measured (top panel) and modeled (bottom panel) particle size distribution is plotted in Fig. 8. The presented modeled result is for $\gamma=1$. The 5 cyclic behavior of the particle number concentration can be seen in panels, but smaller details cannot be seen in model run after $8 \mathrm{~h}$ simulation.

\section{Discussion}

The modeled gas-phase profile in our 1-product model corresponds well to that estimated from the growth rate data. Concentrations of that magnitude can be obtained 10 if the molar yield of the gas is in the range $\sim 0.1-0.4$ by presuming ambient conditions used in this study, whereas molecules are produced to the gas-phase at a rate of $0.5-2 \times 10^{13} \mathrm{~m}_{\text {air }}^{-3} \mathrm{~s}^{-1}$. Molecules' loss rate to nucleation is by far smaller (of magnitude $1 \times 10^{8} \mathrm{~m}_{\text {air }}^{-3} \mathrm{~s}^{-1}$ ). The formed gas participates here both in condensational growth and nucleation, so the molecules' loss rate because of nucleation is negligible. Hence the 15 main factors shaping concentration of the molecules are the formation rate of the oxidation reaction and the loss by sink and by air exchange. If nucleation was caused by another compound that does not condense onto the particles, then the molar yield of this compound would be much smaller compared to the values used here. For example, in case of a molar yield of 0.001 (presuming the oxidation and particle formation rates mentioned earlier), we could have another gas present in the gas-phase that possess a concentration of magnitude $10^{14} \mathrm{~m}_{\text {air }}^{-3}$ after $10 \mathrm{~h}$ simulation time. The presence of another compound as the main participant in nucleation might hold true in the chamber conditions (Hao et al., 2009). Another interesting observation is that if we estimate the gas concentration from the growth rates and compare those to the new particle formation (nucleation) rates (estimated for particles of diameter $\geq 15 \mathrm{~nm}$ ) from raw data, we can evaluate nucleation rate constants for different kinetics schemes that are very close to those obtained by trial-and-error in our model runs.

GMDD

$4,385-417,2011$

\section{Modeling of aerosol dynamics in a mixed flow chamber}

M. Vesterinen et al.

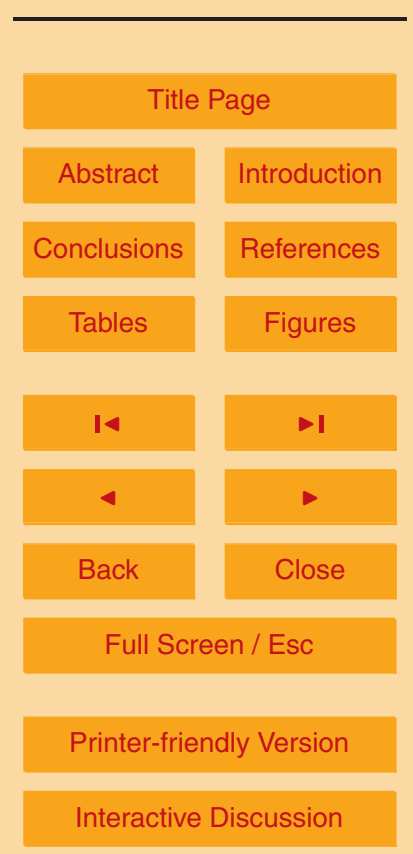

Interactive Discussion 
In the model, the coupling between nucleation rate and gas-phase concentration of the condensable compound requires more explanation. High concentration values can be obtained if the life time of the species is long in the gas phase. This is possible only if processes that decrease the concentration of the molecules (condensational growth, 5 nucleation or wall loss/air exchange) remain sufficiently negligible. Nucleation, on the other hand, increases the aerosol sink as the total surface area of particles increases rapidly along with new particles. Now, if the formation of new particles is increased by setting higher values for the nucleation rate constant, a decrease in gas-phase concentrations follows later that may lead to cyclic behavior. This was demonstrated in 10 the model runs simply by increasing the nucleation rate constant and by lowering the molar yield term: for example, in the case of $\gamma=1$, if we increased the nucleation rate constant by a factor 5 and decreased the molar yield to 0.27 (see Fig. 4), we obtained a damped cyclic profile (not presented here). In that case the modeled values began to oscillate and there were 13 "nucleation bursts" during the time span of $26 \mathrm{~h}$. This difficulty might be avoided by using a modified 2-product model.

The results indicate strongly that to investigate the NC and sink profiles in detail, the flow chamber simulations require additional information about the $\mathrm{HC}$ concentration profiles inside the chamber. It is likely that our data lacks of information due to the different processes caused by natural HC sources (e.g. plants' photosynthesis) and gas-phase chemistry. For example, the illumination conditions inside the chamber were changed during night time and a careful investigation of Figs. 3 and 4 indicates that this might affect nucleation of new particles as well: after $12 \mathrm{~h}$ one can see a weak nucleation burst. This seems not to be reproducible with our model, where continuous nucleation rates are settled to constant values already after $6-7 \mathrm{~h}$ in each simulation case. Therefore, understanding of the $\mathrm{HC}$ concentration changes are of importance here.

According to our simulation results, it is difficult to obtain unambiguous model response for chosen modeling parameters. Of certain values of the controllable parameters of the system, it is even possible to sustain oscillations without noticeable damped
GMDD

4, 385-417, 2011

\section{Modeling of aerosol dynamics in a mixed flow chamber}

M. Vesterinen et al.

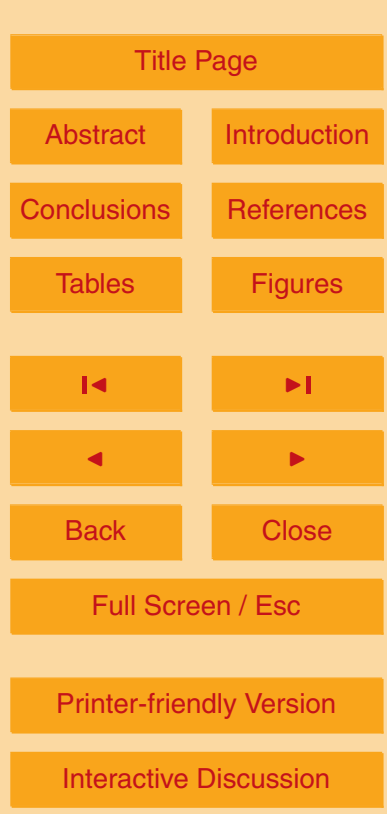


behavior (not presented here, however). This might also indicate that the investigated system is non-linear at nature and small changes in initial situation might have a larger effect on the final results. In addition, the independent variables used in the model are adjustable, thus turning the problem basically to a "curve fitting" problem. We did 5 not attempt to use intelligent optimizing algorithms in the main program runs and there is a reason to suspect that the coupled behavior between the model equations could affect the convergence properties of the modeled system.

In addition, the hydrocarbon and CG net wall losses were not considered here. However, some authors have investigated the effect of gas wall losses to the SOA formation 10 and results are rather two-fold: for example, the losses of $\alpha$-pinene to the chamber walls can be considered minimal (Verheggen et al., 2007) whereas recent simulation studies by Saathoff et al. (2008) suggest a different behavior. In addition to these, CG concentration is affected by the carrier gas flow. In this study, the total hydrocarbon concentration was monitored at different points of the measurement chamber, but here the measured outlet concentrations were determined to work as indicative "inbox" hydrocarbon concentration to obtain an optimal result for the reaction rate in the first stage of the modeling work. Therefore, the linear concentration profile of $\mathrm{HC}$ included implicitly the information about the wall losses, and there was no need to consider it further. The oxidant inlet concentration, on the other hand, was kept fixed during the experiment. If the ozone concentration inside the chamber is negligible at first, the inlet concentration of $200 \mathrm{ppb}$ causes it to approach a limiting value asymptotically (presuming that the air exchange effect is not too large as it is not in this work). The large amount of ozone ensures that even if the wall loss was taken into account, its relative importance would be rather small.

\section{Conclusions}

We have developed an aerosol dynamics model for analyzing particle formation in a mixed flow chamber, in which VOC's from Norway spruce seedlings are oxidized and
GMDD

$4,385-417,2011$

\section{Modeling of aerosol dynamics in a mixed flow chamber}

M. Vesterinen et al.

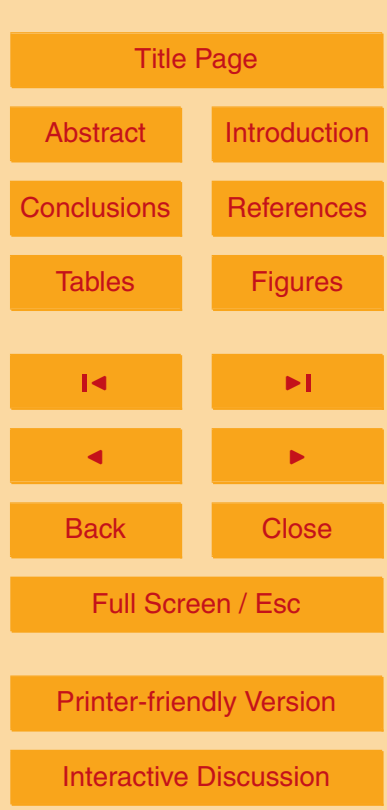

Interactive Discussion 
form condensable vapors. The observed aerosol dynamics is a cyclic process in which particle formation events result in a decrease of the condensable vapor concentrations and a high scavenging rate of the newly formed particles - resulting in a quenching of particle formation. Deposition and thus a reduction in the scavenging rate then 5 again gradually increases the vapor concentrations and a new nucleation event may be observed.

The simulations show satisfactory results although the studied system is highly coupled and very sensitive to the model parameter values. Both the cyclic features of the aerosol dynamics as well as the time evolution of the total number concentration and 10 the condensation sink are reproduced reasonably well. The model was tested in four different cases using different functional forms for nucleation. In all simulation cases, the condensable gas was assumed semi-volatile and therefore the Kelvin effect had to be included in the calculations. The wall loss rate as a function of size was estimated using a separate experiment with the same setup and conditions.

15 In the experiments, the newly formed particles were observed to grow up to diameters of $300 \mathrm{~nm}$ and above. In the simulations, even if we used a molar yield of the formed vapor as high as 0.35 , which is twice as large as the value estimated from experimental growth rate data, we could not see growth extending that far. Therefore, other immediate first generation oxidation products might have participated in the nucleation or the condensational growth process.

The detailed nucleation kinetics of the gas phase compounds remains unknown. We presumed here that the new particles are formed via a process that has an analogy with chemical process of $\gamma$ th order. By using a simple power law function depending on the gas-phase concentration, and using different integer values for the power-law exponent $\gamma$, we were able to satisfactorily match the time evolution of the aerosol number concentration and condensation sink as a function of time despite the fact that the exact details of the nucleation process remained unclear. The best results for the time evolution of the number concentration were obtained with low values ( 0 and 1$)$ for $\gamma$, whereas the performance of the model with respect to the condensation sink seemed
GMDD

4, 385-417, 2011

\section{Modeling of aerosol dynamics in a mixed flow chamber}

M. Vesterinen et al.

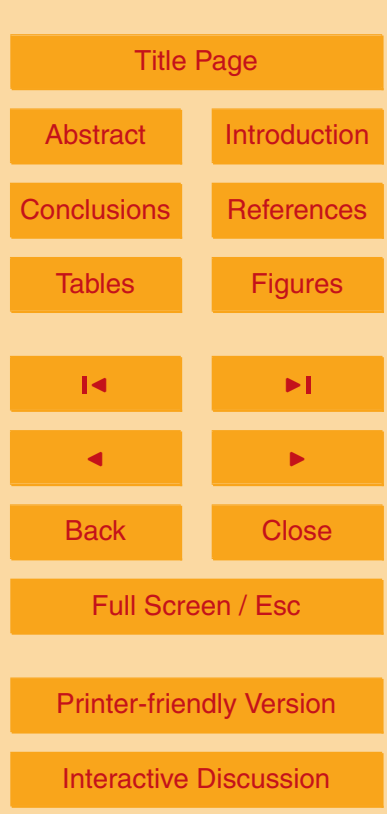

405 
to be rather independent on the factor $\gamma$. This indicates that the nucleating compound's gas-phase profile must be nearly constant as a function of time or changes in the profile are small in relevant time scales in the work. The results are in accordance with recent findings from field experiments suggesting that the particle formation rate is roughly 5 proportional to the condensable vapor concentration. However, the exact kinetics of the process cannot be determined based on these model runs only.

\section{References}

Badger, E. H. M. and Dryden, I. G. C.: The formation of gum particles in coal gas, Trans. Faraday Soc., 35, 607, 1939.

Bowman, F. M., Odum, J. R., Seinfeld, J. H., and Pandis, S. N.: Mathematical model for gasparticle partitioning of secondary organic aerosols, Atmos. Environ., 31, 3921-3931, 1997.

Calogirou, A., Larsen, B. R., and Kotzias, D.: Gas-phase terpene oxidation products: a review, Atmos. Environ., 33, 1423-1439, 1999.

Capouet, M., Müller, J.-F., Ceulemans, K., Compernolle, S., Vereecken, L., and Peeters, J.: 15 Modeling aerosol formation in $\alpha$-pinene photo-oxidation experiments, J. Geophys. Res., 113, D02308, doi:10.1029/2007JD008995, 2008.

Cocker, D. R., Clegg, S. L., Flagan, R. C., and Seinfeld, J. H.: The effect of water on gasparticle partitioning of secondary organic aerosol. Part I: alpha-pinene/ozone system, Atmos. Environ., 35, 6049-6072, 2001.

Crump, J. G. and Seinfeld, J. H.: Aerosol behavior in the continuous stirred tank reactor, AIChE J., 26, 4, 610-616, 1980.

Crump, J. G. and Seinfeld, J. H.: Turbulent deposition and gravitational sedimentation of an aerosol in a vessel of arbitrary shape, J. Aerosol Sci., 12, 405-415, 1981.

Crump, J. G., Flagan, R. C., and Seinfeld, J. H.: Particle wall loss rates in vessels, Aerosol Sci. 25 Technol., 2, 303-309, 1983.

Dal Maso, M., Kulmala, M., Lehtinen, K. E. J., Mäkelä, J. M., Aalto, P., and O'Dowd, C. D.: Condensation and coagulation sinks and formation of nucleation mode particles in coastal and boreal forest boundary layers, J. Geophys. Res., 107, 8097, doi:10.1029/2001JD001053, 2002.

\section{GMDD}

$4,385-417,2011$

\section{Modeling of aerosol dynamics in a mixed flow chamber}

M. Vesterinen et al.

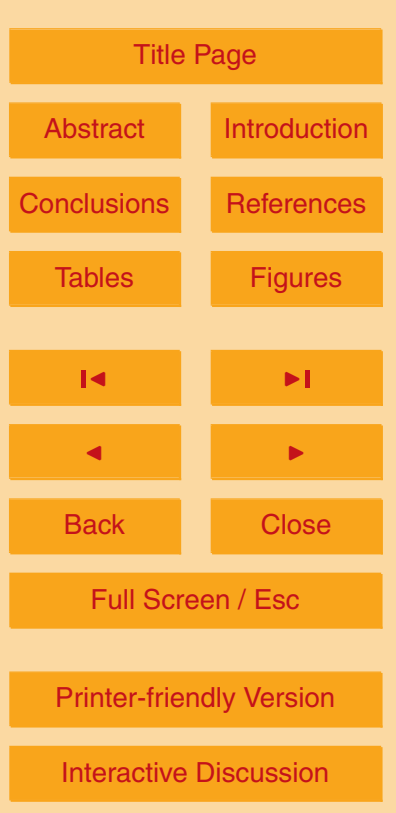


Friedlander, S. K.: Dynamics of aerosol formation by chemical reaction, Fourth International Conference on Physicochemical Hydrodynamics, 404, 354-364, 1983.

Fuchs, N. and Sutugin, A.: Highly Dispersed Aerosols, Ann Arbor Sci./Pergamon, New York, 1971.

5 Guenther, A., Hewitt, C. N., Erickson, D., Fall, R., Geron, C., Graedel, T., Harley, R., Klinger, L., Lerdau, M., Mckay, W. A., Pierce, T., Scholes, B., Steinbrecher, R., Tallamraju, R., Taylor, J., and Zimmerman, P.: A global-model of natural volatile organic-compound emissions, J. Geophys. Res., 100, 8873-8892, 1995.

Hamed, A., Joutsensaari, J., Mikkonen, S., Sogacheva, L., Dal Maso, M., Kulmala, M., Cavalli, F., Fuzzi, S., Facchini, M. C., Decesari, S., Mircea, M., Lehtinen, K. E. J., and Laaksonen, A.: Nucleation and growth of new particles in Po Valley, Italy, Atmos. Chem. Phys., 7, 355-376, doi:10.5194/acp-7-355-2007, 2007.

Hao, L. Q., Yli-Pirilä, P., Tiitta, P., Romakkaniemi, S., Vaattovaara, P., Kajos, M. K., Rinne, J., Heijari, J., Kortelainen, A., Miettinen, P., Kroll, J. H., Holopainen, J. K., Smith, J. N., Joutsensaari, J., Kulmala, M., Worsnop, D. R., and Laaksonen, A.: New particle formation from the oxidation of direct emissions of pine seedlings, Atmos. Chem. Phys., 9, 8121-8137, doi:10.5194/acp-9-8121-2009, 2009.

Heist, R. H., Fuchs, A., and Agarwal, G.: Multiple oscillations at high rates of homogeneous nucleation, Chem. Eng. Com., 5, 1, 1980.

Hoppel, W., Fitzgerald, J., Frick, G., Caffrey, P., Pasternack, L., Hegg, D., Gao, S., Leaitch, R., Shantz, N., Cantrell, C., Albrechcinski, T., Ambrusko, J., and Sullivan, W.: Particle formation and growth from ozonolysis of $\alpha$-pinene, J. Geophys. Res., 106, D21, 27603-27618, 2001.

Hussein, T., Hruška, A., Dohányosová, P., Dumbová, L., Hemerka, J., Kulmala, M., and Smolík, J.: Deposition rates on smooth surfaces and coagulation of aerosol particles inside a test chamber, Atmos. Environ., 43, 905-914, 2009.

Jaatinen, A.: Atmospheric nucleation in Italy, German and Finland: a comparative study, a master of science thesis, University of Kuopio, 2008.

Jimenez, J. L., Canagaratna, M. R., Donahue, N. M., Prévôt, A. S. H., Zhang, Q., Kroll, J. H., DeCarlo, P. F., Allan, J. D., Coe, H., Ng, N. L., Aiken, A. C., Docherty, K. S., Ulbrich, I. M., Grieshop, A. P., Robinson, A. L., Duplissy, J., Smith, J. D., Wilson, K. R., Lanz, V. A., Hueglin, C., Sun, Y. L., Tian, J., Laaksonen, A., Raatikainen, T., Rautiainen, J., Vaattovaara, P., Ehn, M., Kulmala, M., Tomlinson, J. M., Collins, D. R., Cubison, M. J. E., Dunlea, J., Huffman, J. A., Onasch, T. B., Alfarra, M. R., Williams, P. I., Bower, K., Kondo, Y.,

\section{GMDD}

$4,385-417,2011$

\section{Modeling of aerosol dynamics in a mixed flow chamber}

M. Vesterinen et al.

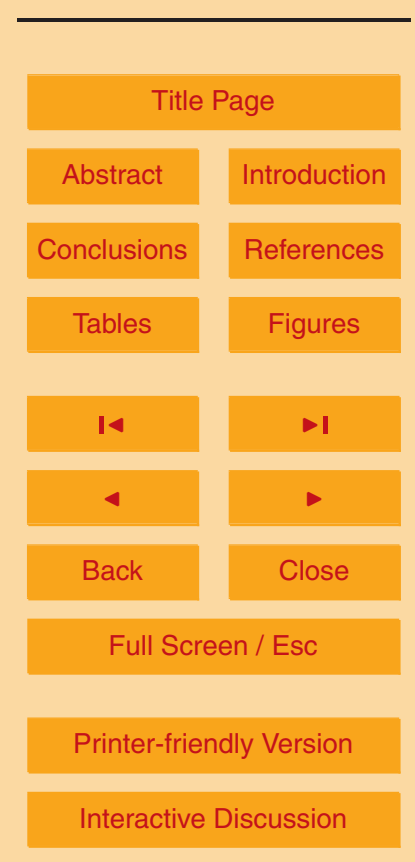


Schneider, J., Drewnick, F., Borrmann, S., Weimer, S., Demerjian, K., Salcedo, D., Cottrell, L., Griffin, R., Takami, A., Miyoshi, T., Hatakeyama, S., Shimono, A., Sun, J. Y., Zhang, Y. M., Dzepina, K., Kimmel, J. R., Sueper, D., Jayne, J. T., Herndon, S. C., Trimborn, A. M., Williams, L. R., Wood, E. C., Middlebrook, A. M., Kolb, C. E., Baltensperger, U., and Worsnop, D. R.: Evolution of organic aerosols in the atmosphere, Science, 326, 15251529, 2009.

Kanakidou, M., Seinfeld, J. H., Pandis, S. N., Barnes, I., Dentener, F. J., Facchini, M. C., Van Dingenen, R., Ervens, B., Nenes, A., Nielsen, C. J., Swietlicki, E., Putaud, J. P., Balkanski, Y., Fuzzi, S., Horth, J., Moortgat, G. K., Winterhalter, R., Myhre, C. E. L., Tsigaridis, K., Vignati, E., Stephanou, E. G., and Wilson, J.: Organic aerosol and global climate modelling: a review, Atmos. Chem. Phys., 5, 1053-1123, doi:10.5194/acp-5-1053-2005, 2005.

Kleindienst, T. E., Smith, D. F., Li, W., Edney, E. O., Driscoll, D. J., Speer, R. E., and Weathers, W. S.: Secondary organic aerosol formation from the oxidation of aromatic hydrocarbons in the presence of dry submicron ammonium sulfate aerosol, Atmos. Environ., 33, 36693681, 1999.

Korhonen, H., Lehtinen, K. E. J., and Kulmala, M.: Multicomponent aerosol dynamics model UHMA: model development and validation, Atmos. Chem. Phys., 4, 757-771, doi:10.5194/acp-4-757-2004, 2004.

Kulmala, M., Toivonen, A., Mäkelä, J. M., and Laaksonen, A.: Analysis of the growth of nucleation mode particles observed in Boreal forest, Tellus B, 50, 449-462, 1998.

Kulmala, M., Dal Maso, M., Mäkelä, J. M., Pirjola, L., Väkevä, M., Aalto, P., Miikkulainen, P., Hämeri, K., and O'Dowd, C. D.: On the formation, growth and composition of nucleation mode particles, Tellus B, 53, 479-490, 2001.

McMurry, P. H. and Grosjean, D.: Gas and aerosol wall losses in teflon film smog chambers, Environ. Sci. Technol., 19, 1176-1182, 1985.

McMurry, P. H. and Rader, D. J.: Aerosol wall losses in electrically charged chambers, Aerosol Sci. Technol., 4, 249-268, 1985.

Nelder, M. and Mead, R.: A simplex method for function minimization, Comput. J., 7, 4, 308313, 1965.

30 Odum, J. R., Hoffman, T., Bowman, F., Collins, D., Flagan, R. C., and Seinfeld, J. H.: Gas/particle partitioning and secondary organic aerosol yields, Environ. Sci. Technol., 30, 2580-2585, 1996.

Park, S. H., Kim, H. O., Han, Y. T., Kwon, S. B., and Lee, K. W.: Wall loss rate of polydispersed

\section{GMDD}

$4,385-417,2011$

\section{Modeling of aerosol dynamics in a mixed flow chamber}

M. Vesterinen et al.

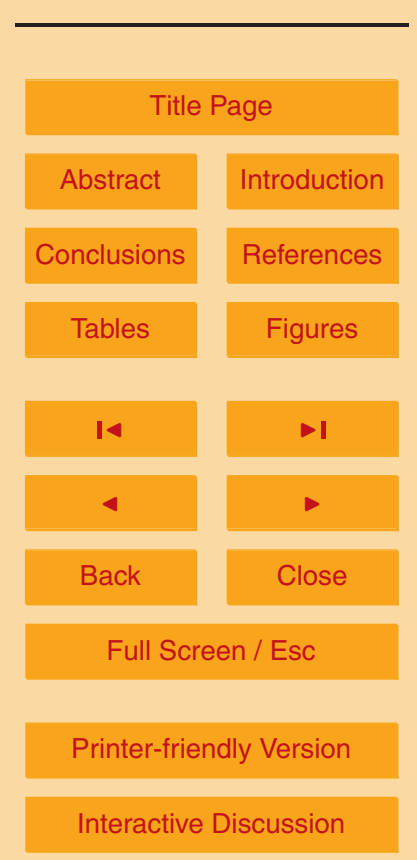

Interactive Discussion 
aerosols, Aerosol Sci. Technol., 35, 710-717, 2001.

Pankow, J. F.: An absorption model of gas/particle partitioning of organic compounds in the atmosphere, Atmos. Environ., 28, 185-188, 1994a.

Pankow, J. F.: An absorption model of gas/particle partitioning involved in the formation of secondary organic aerosol, Atmos. Environ., 28, 189-193, 1994b.

Pratsinis, S. E., Friedlander, S. K., and Pearlstein, A. J.: Aerosol reactor theory: stability and dynamics of a continuous stirred tank aerosol reactor, AIChE J., 32, 2, 177-185, 1986.

Reid, R. C., Prausnitz, J. M., and Poling, B. E.: The properties of Gases and Liquids, fourth edn., McGraw-Hill, New York, 1987.

10 Reiss, H., Marvin, D. C., and Heist, R. H.: The use of nucleation and growth as a tool in chemical physics, J. Colloid Interf. Sci., 58, 125, 1977.

Saathoff, H., Naumann, K.-H., Möhler, O., Jonsson, Å. M., Hallquist, M., Kiendler-Scharr, A., Mentel, Th. F., Tillmann, R., and Schurath, U.: Temperature dependence of yields of secondary organic aerosols from the ozonolysis of $\alpha$-pinene and limonene, Atmos. Chem. Phys., 9, 1551-1577, doi:10.5194/acp-9-1551-2009, 2009.

Seinfeld, J. H. and Pandis, S. N.: Atmospheric Chemistry and Physics, John Wiley \& Sons Inc., New York, 649-682, 1998.

Seinfeld, J. H., Kleindienst, T. E., Edney, E. O., and Cohen, J. B.: Aerosol growth in a steadystate, continuous flow chamber: application to studies of secondary aerosol formation, Aerosol Sci. Technol., 37, 728-734, 2003.

Svendby, T. M., Lazaridis, M., and Torseth, K.: Temperature dependent secondary organic aerosol formation from terpenes and aromatics, J. Atmos. Chem., 59, 25-46, 2008.

Turco, R. P., Hamill, P., Toon, O. B., Whitten, R. C., and Kiang, C. S.: The NASA-Ames Research Center stratospheric aerosol model: 1. Physical processes and computational analogs, Nasa Technical Publications, 1362, iii-94, 1979.

VanReken, T. M., Greenberg, J. P., Harley, P. C., Guenther, A. B., and Smith, J. N.: Direct measurement of particle formation and growth from the oxidation of biogenic emissions, Atmos. Chem. Phys., 6, 4403-4413, doi:10.5194/acp-6-4403-2006, 2006.

Verheggen, B., Mozurkewich, M., Caffrey, P., Frick, G., Hoppel, W., and Sullivan, W.: $\alpha$-pinene 30 oxidation in the presence of seed aerosol: estimates of nucleation rates, growth rates and yield, Environ. Sci. Technol., 41, 6046-6051, 2007.

Yu, J., Cocker, D. R., Griffin, R. J., Flagan, R. C., and Seinfeld, J. H.: Gas-phase ozone oxidation of monoterpenes: gaseous and particulate products, J. Atmos. Chem., 34, 207-258, 1999.
GMDD

4, 385-417, 2011

\section{Modeling of aerosol dynamics in a mixed flow chamber}

M. Vesterinen et al.

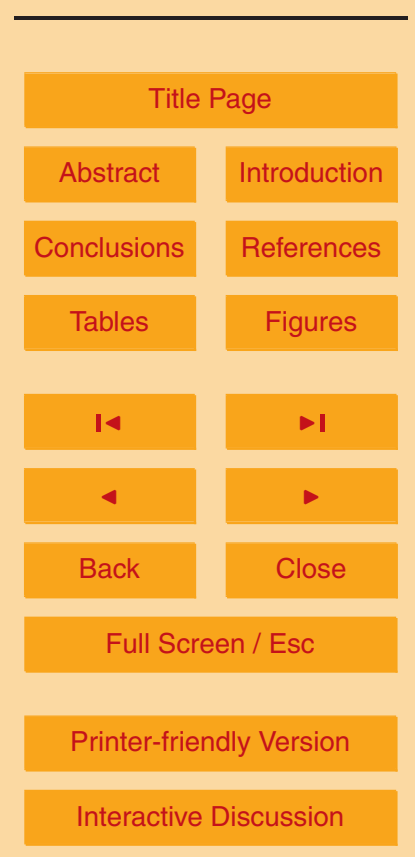




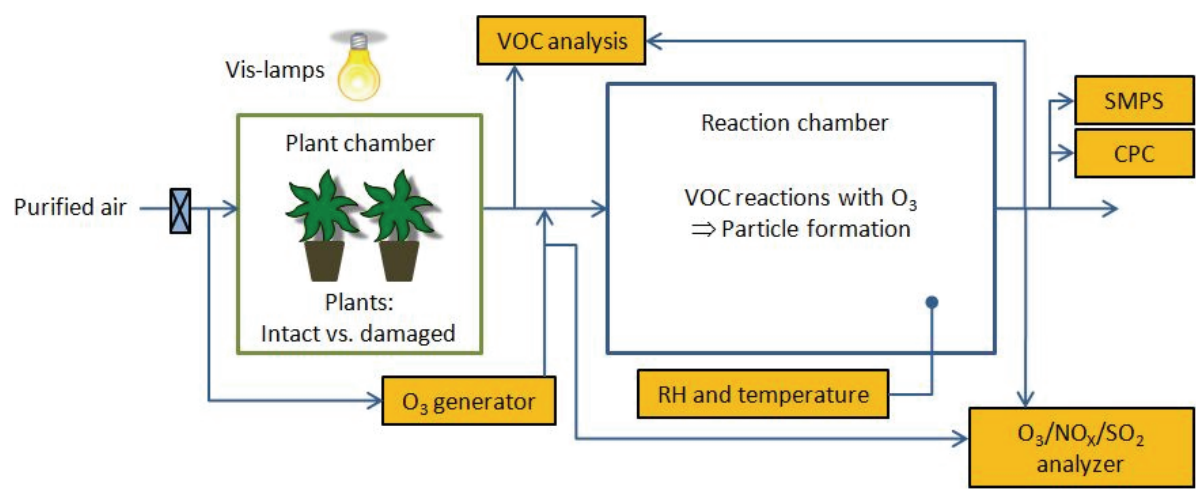

\section{GMDD}

4, 385-417, 2011

\section{Modeling of aerosol dynamics in a mixed \\ flow chamber}

M. Vesterinen et al.

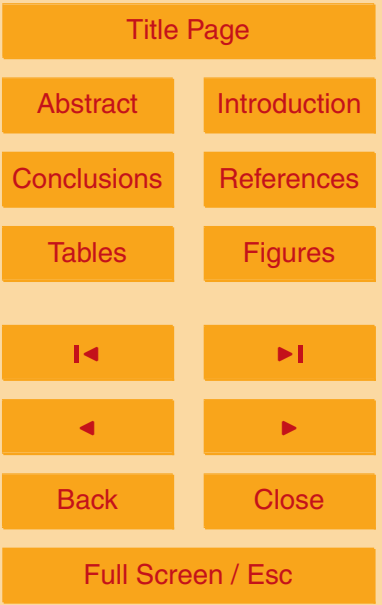

Printer-friendly Version

Interactive Discussion 


\section{GMDD}

\section{4, 385-417, 2011}
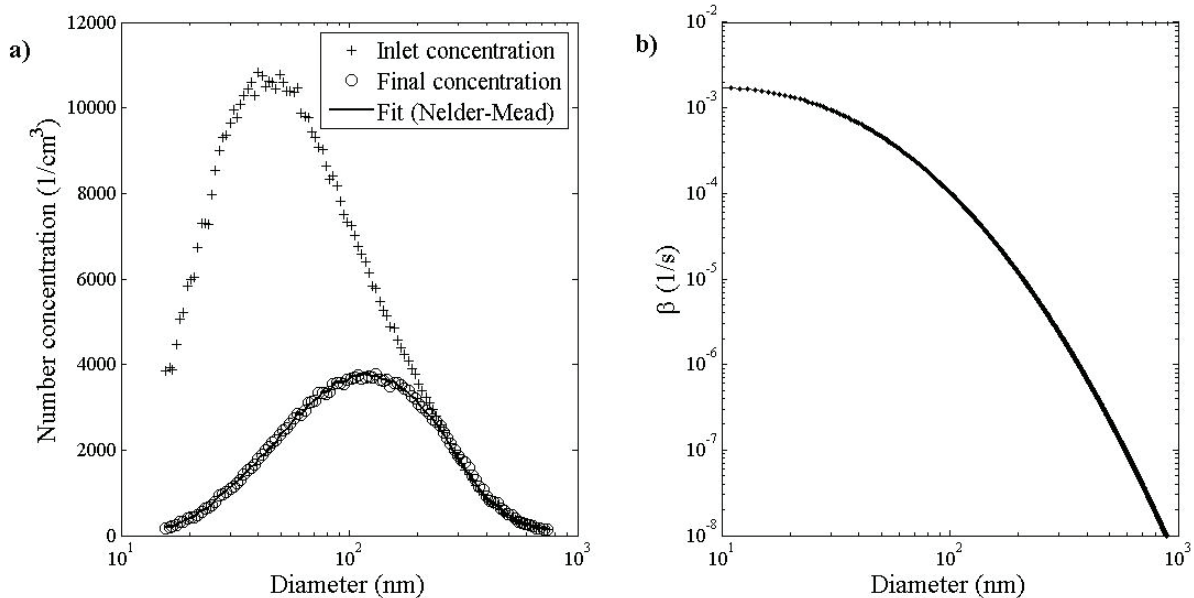

\section{Modeling of aerosol dynamics in a mixed flow chamber}

M. Vesterinen et al.

Fig. 2. (a) Particle number size distribution measured at the inlet $(+)$ at the beginning of the experiment and the distribution (o) after $3 \mathrm{~h}$ inside the chamber (particle population in steadystate, where feed of aerosols is kept constant). The modeled distribution is plotted using solid line. (b) The wall loss coefficient as a function of particle diameter. The shape of the curve follows that of Eq. (5) and the values for $A, B, C$ and $D$ are: $-2.092537,10.29880,-10.97090$ and 0.5636268 (diameters must be given in nanometers).

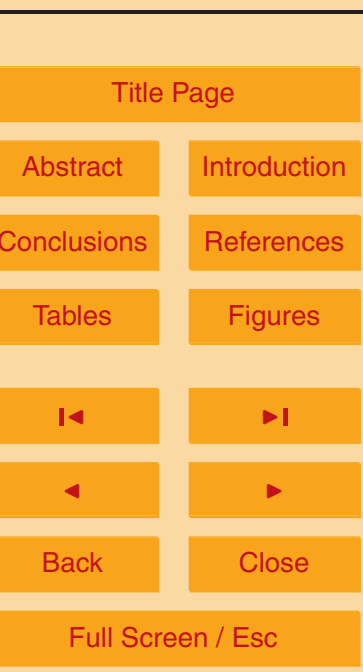

Printer-friendly Version

Interactive Discussion 


\section{GMDD}

$4,385-417,2011$

a)

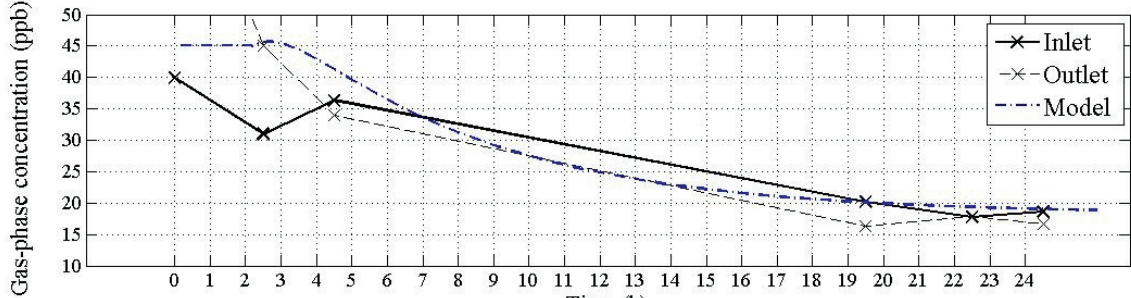

b)

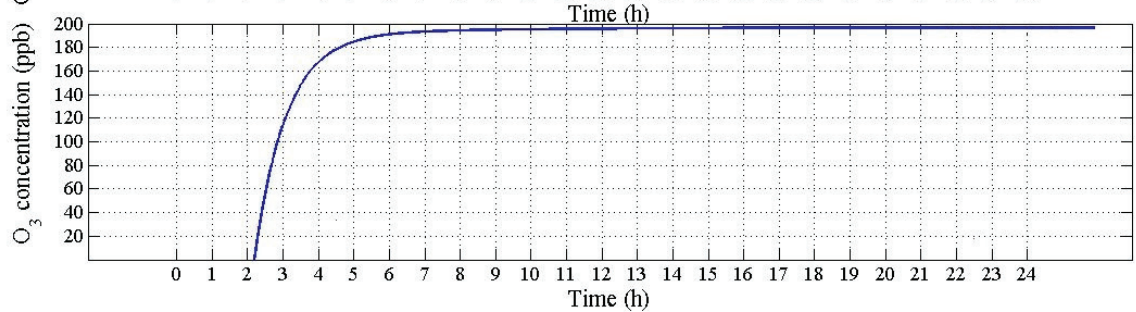

Fig. 3. (a) Total $\mathrm{HC}$ concentrations $\left(\mathrm{m}_{\text {air }}^{-3}\right)$ at inlet, outlet and inside the flow chamber (estimated by using the constructed model) and (b) estimated ozone concentration (ppb). The feed of $\mathrm{HC}$ was started before the feed of ozone was initialized after $2.2 \mathrm{~h}$. In (a) the actual measured values of inlet and outlet concentrations are marked using " $X$ " and concentration profiles between measured values are presumed to behave linearly. For simplicity, the difference between inlet and outlet concentrations of $\mathrm{HC}$ were kept constant $(3 \mathrm{ppb})$ during simulations in the model runs. This is based on (a): the profiles are nearly parallel and differ by a value of ca. $3 \mathrm{ppb}$ between $4.5-19.5 \mathrm{~h}$ after the experiment was initialized. The used value of oxidation reaction rate is $1 \times 10^{-23} \mathrm{~m}_{\mathrm{air}}^{-3} \mathrm{~s}^{-1}$.

\section{Modeling of aerosol dynamics in a mixed flow chamber}

M. Vesterinen et al.

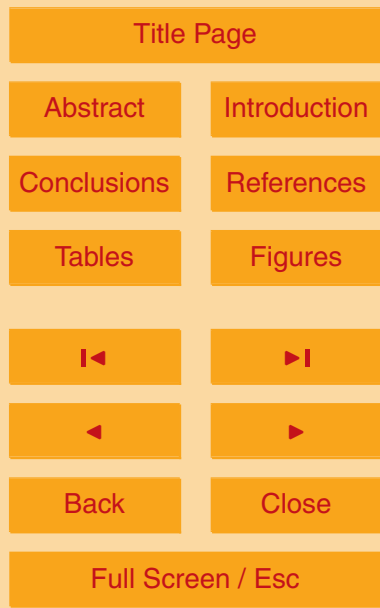

Printer-friendly Version

Interactive Discussion 

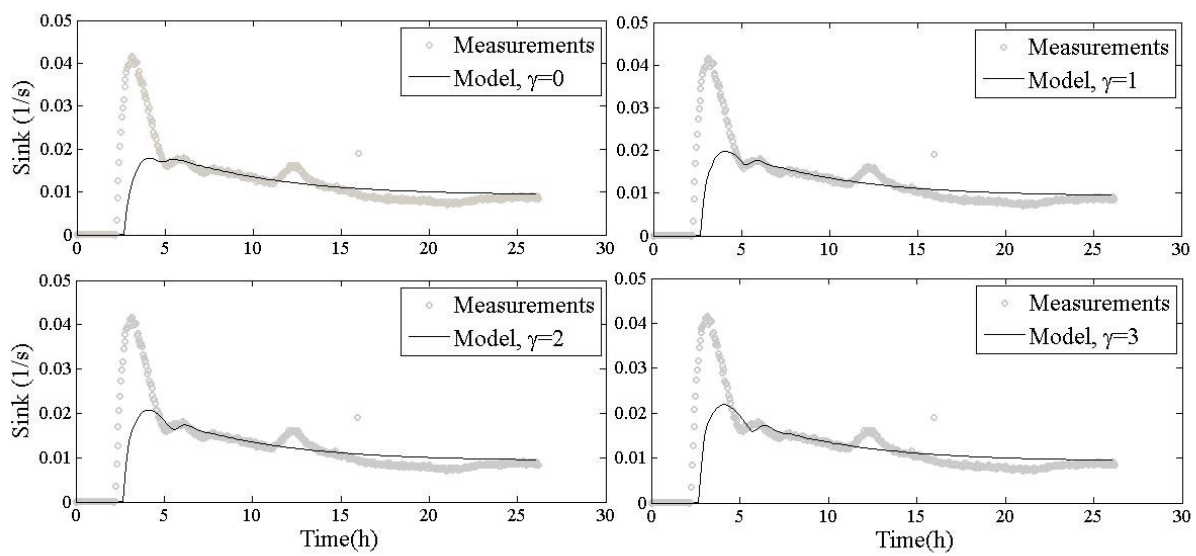

Fig. 4. Measured and modeled condensational sink as a function of time. The factor $\gamma$ is varied between $0-3$. Oxidation reaction rate constant of $\mathrm{HC}$ is set to value $1 \times 10^{-23} \mathrm{~m}_{\text {air }}^{-3} \mathrm{~s}^{-1}$ and the molar yield of condensable gas to value 0.35 in all cases. Saturation vapor concentration of the compound was kept constant in all cases as well $\left(1 \times 10^{12} \mathrm{~m}_{\text {air }}^{-3}\right)$. Values of the nucleation rate constants ( $\frac{A}{\gamma}$, see Eq. 2) found were to be: $0.7 \times 10^{8} \mathrm{~m}_{\text {air }}^{-3} \mathrm{~s}^{-1}$ for $\gamma=0,1.8 \times 10^{-7} \mathrm{~s}^{-1}$ for $\gamma=1$, $3.3 \times 10^{-22} \mathrm{~m}_{\text {air }}^{-3} \mathrm{~s}^{-1}$ for $\gamma=2$ and $6.0 \times 10^{-37} \mathrm{~m}_{\text {air }}^{6} \mathrm{~s}^{-1}$ for $\gamma=3$.
GMDD

$4,385-417,2011$

\section{Modeling of aerosol dynamics in a mixed flow chamber}

M. Vesterinen et al.

Title Page

Abstract

Introduction

Conclusions

References

Tables

Figures

14

$\rightarrow$

4

Back

Close

Full Screen / Esc

Printer-friendly Version

Interactive Discussion 


\section{GMDD}

$4,385-417,2011$
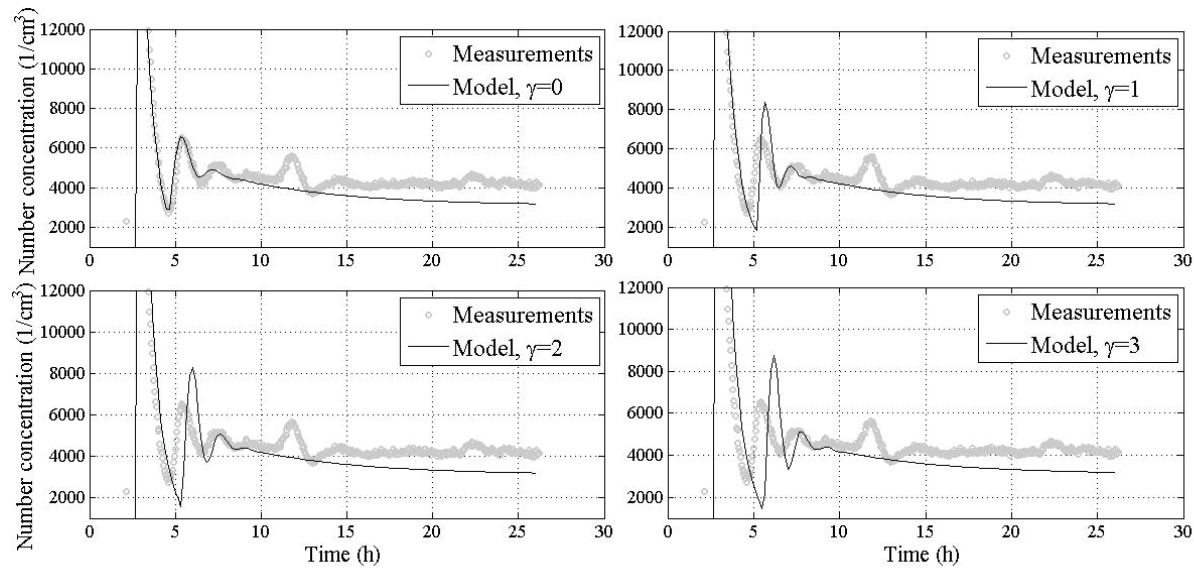

Fig. 5. Measured and modeled aerosol particle number concentration as a function of time. The factor $\gamma$ is varied between $0-3$. Oxidation reaction rate, the molar yield of condensable gas, saturation vapor concentration of the compound and values of nucleation rate constants are the same as in Fig. 4.

\section{Modeling of aerosol dynamics in a mixed flow chamber \\ M. Vesterinen et al.

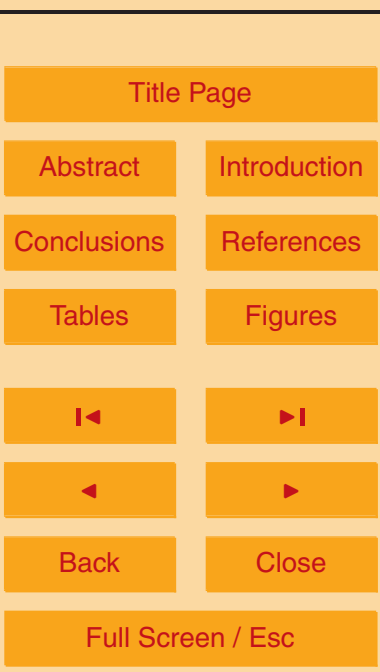

Printer-friendly Version

Interactive Discussion 


\section{GMDD}

$4,385-417,2011$

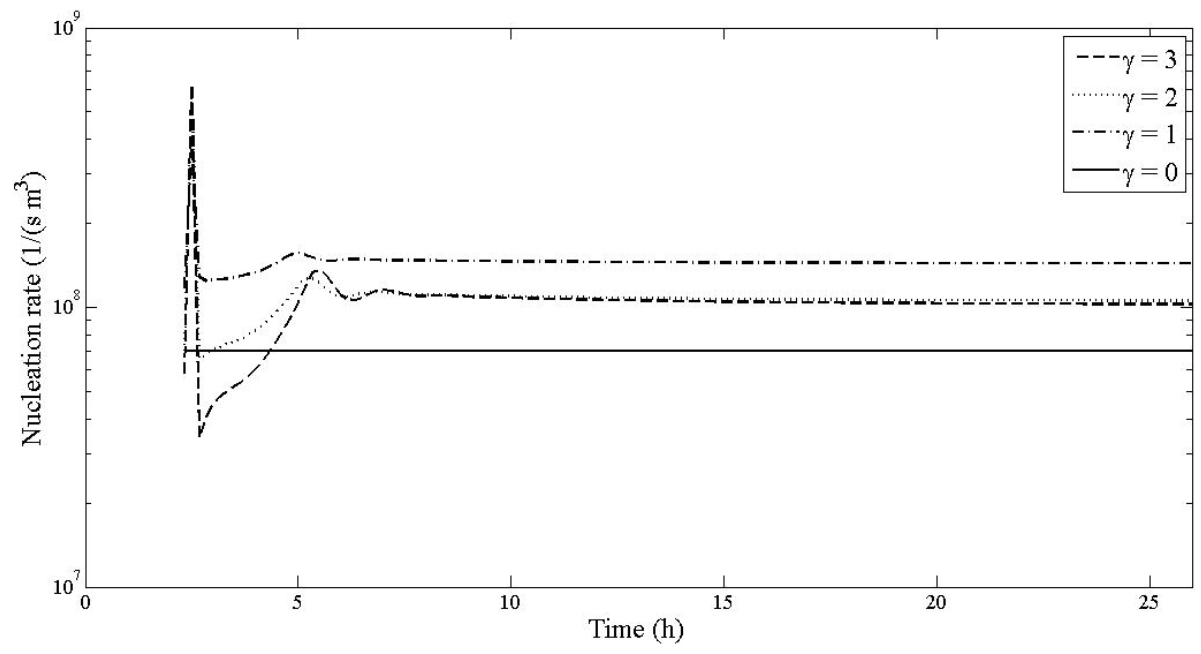

\section{Modeling of aerosol dynamics in a mixed flow chamber}

M. Vesterinen et al.

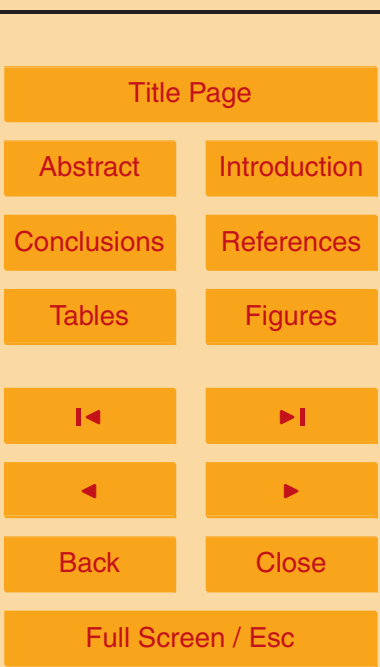

Fig. 6. The modeled nucleation rate of the particles (logarithmic scale) in the first size class as a function of time. The ozone feed begins after $2.2 \mathrm{~h}$ and almost simultaneously, new particles start to nucleate. Particle formation rate depends on the gas-phase concentration of the condensable gas. The factor $\gamma$ is varied between $0-3$. Oxidation reaction rate, the molar yield of condensable gas, saturation vapor concentration of the compound and values of nucleation rate constants are the same as in Figs. 3 and 4.

Printer-friendly Version

Interactive Discussion 


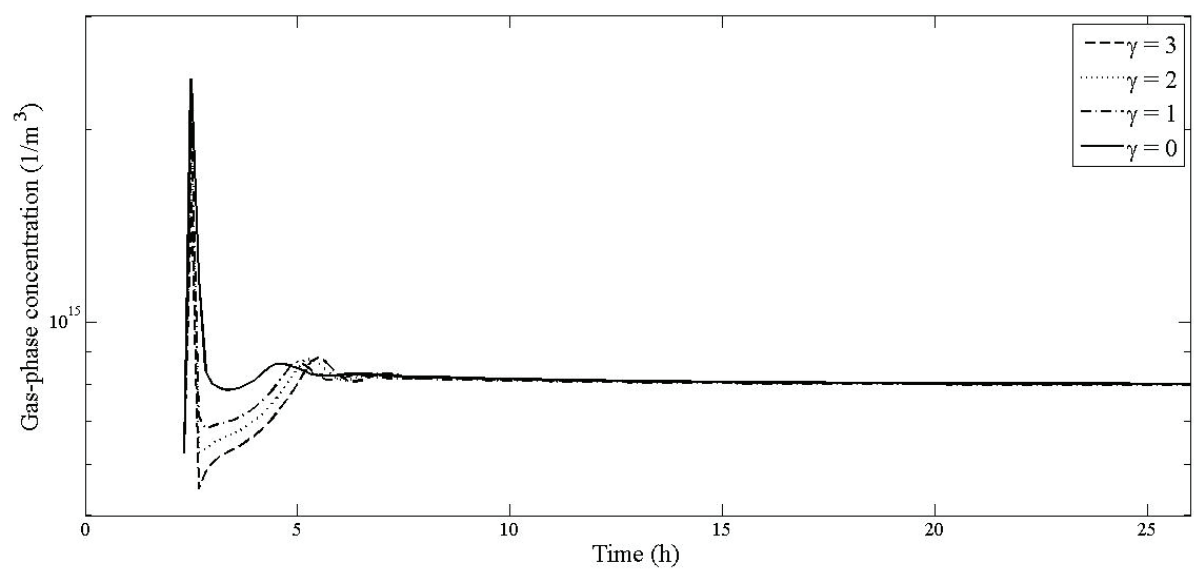

Fig. 7. The modeled gas-phase concentration (logarithmic scale) of the condensable gas as a function of time. The factor $\gamma$ is varied between $0-3$.

\section{GMDD}

$4,385-417,2011$

\section{Modeling of aerosol dynamics in a mixed flow chamber}

M. Vesterinen et al.

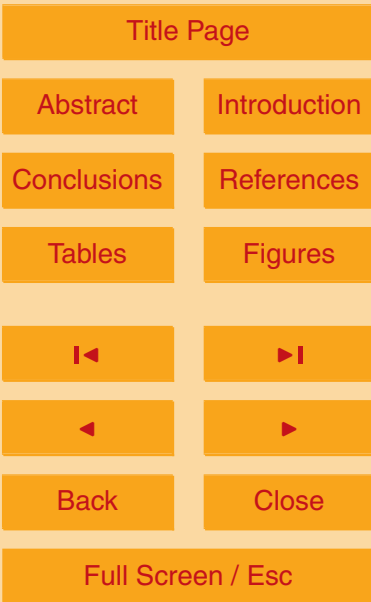

Printer-friendly Version

Interactive Discussion 


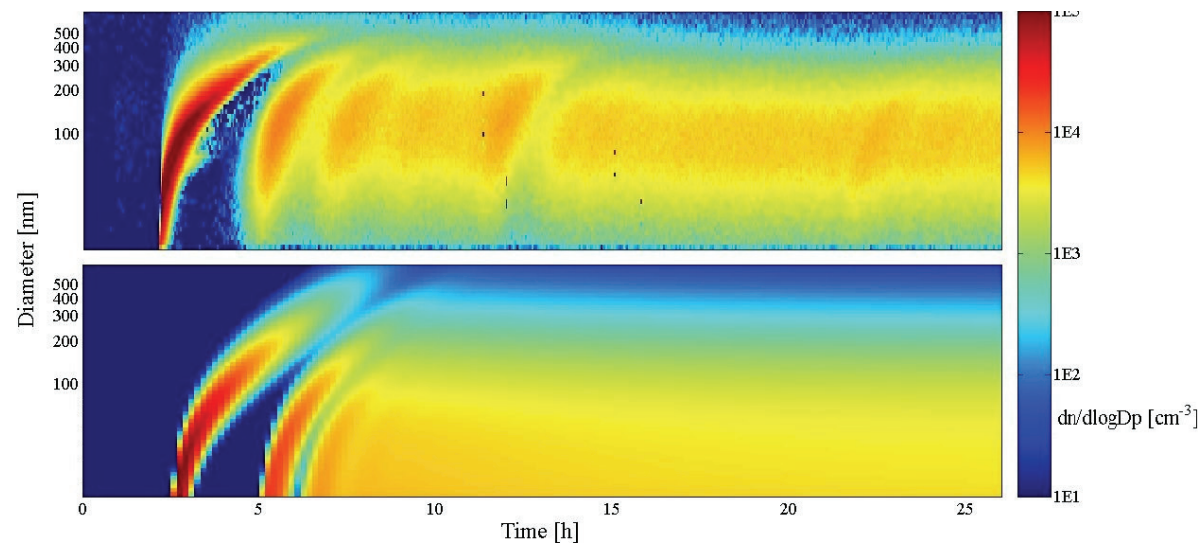

Fig. 8. The aerosol particle number concentration as a function of time and particle diameter. In the upper figure: the measured data. The lower figure: the modeled results in the cases of $\gamma=1$. The colorbar on the right side of Fig. 8 describes the number concentration of the particles.

\section{GMDD}

4, 385-417, 2011

\section{Modeling of aerosol dynamics in a mixed flow chamber}

M. Vesterinen et al.

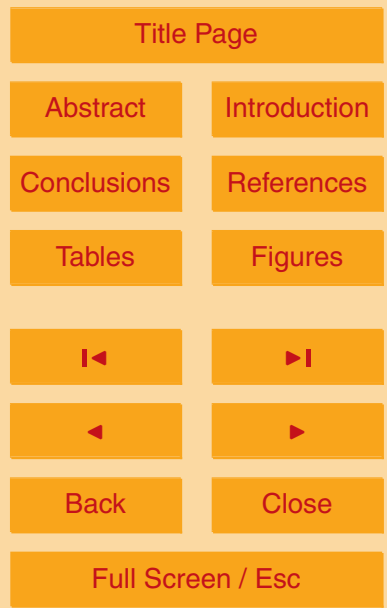

Printer-friendly Version

Interactive Discussion 